\title{
A Rational Design Model for Web Stiffeners
}

\author{
M. Xie ${ }^{a} *$, J. C. Chapman ${ }^{\text {b }}$, R. E. Hobbs ${ }^{\text {b }}$ \\ ${ }^{a}$ Lloyd's Register EMEA, Denburn House, 25 Union Terrace, Aberdeen, AB10 1NN, UK \\ ${ }^{b}$ Department of Civil and Environmental Engineering, Imperial College London, SW7 2AZ, UK
}

\begin{abstract}
Existing design methods for web stiffeners differ widely in concept and in the stiffener size which results. An investigation has been conducted to provide a rational, usable and validated design method for transverse stiffeners. The proposed design method takes account of the axial compression in stiffeners caused by tension field action and external forces, the transverse forces on the stiffeners required to enforce effective division of the web plate, and the tendency for the stiffened plate to buckle overall. Design criteria are established to ensure that the resulting stiffeners do not yield before plate failure, and that the plating is effectively divided into panels. The transverse stiffener dimensions required by the proposed design model have been validated against finite element results for plates subjected to pure shear, and to combined shear and direct in-plane loading. Finally, the stiffener sizes are compared with those required by the existing methods.
\end{abstract}

KEY WORDS: Stiffeners; Stiffener forces; Plate girders; Webs; In-plane Loading; Design; Non-linear analysis; Buckling

\section{Introduction}

Web stiffeners in plate girders have been designed successfully for more than 100 years. However, the design bases and assumptions in different codes and proposals differ widely, and this has an important effect on web thickness/panel size optimisation, and hence on the weight and cost of the stiffened web.

Some approaches are based on critical buckling, taking no account of the effects of initial imperfections in the plate and stiffener, or of post-buckling effects. For these reasons, some methods apply an empirical factor on the required stiffener rigidity obtained from the critical buckling criterion [1]. Other approaches,

\footnotetext{
* Corresponding author. Tel: +44 (0)1224 267400; fax: +44 (0)1224 267401.

Email address: min.xie@lr.org (M. Xie)
} 
including British Standard BS5400 [2], EUROCODE 3 [3] and AASHTO [4], are based principally on the in-plane forces resulting from tension field action and do not give sufficient rational recognition to the out-of-plane forces on the stiffener exerted by panel bending. By designing stiffeners primarily to resist axial forces, the stiffeners required by these approaches tend to become progressively more conservative as the panel depth/length ratio increases $[5,6]$.

Rahal and Harding $[7,8]$ proposed that the stiffeners be designed as a simply supported beam subjected to a distributed lateral load. The design equation for the lateral load was developed by a curve-fitting operation on the lateral reactions acting on a non-deflecting nodal line, which was introduced to replace the stiffener. The effect of axial force caused by tension field action was found to be small for the cases considered, and the effect was therefore neglected. The tallest panel considered in the finite element (FE) analysis had an aspect ratio of 2:1.

For webs in pure shear, a study at Imperial College London $[6,9]$ also demonstrated that the axial forces on the stiffener are of secondary importance, and that out-of-plane forces provide a more rational basis for design. The local panel bending effects and the significance of the tendency for stiffened plates to buckle overall were identified. The studies led to the formulation of a design model that shows good agreement with elasto-plastic finite element analyses for concentric flat bar stiffeners on a two-panel web in pure shear.

In order to improve phenomenological insight and to reduce the complexity to a form suitable for design, the non-linear post-buckling behaviour of stiffened webs subjected to in-plane shear and direct loading (Fig.1) was investigated by experimental, analytical and numerical studies [5]. Tests were conducted on transversely stiffened plate girders with different geometrical configurations and loading arrangements, and the test results were used to validate the elasto-plastic post-buckling behaviour as represented by the FE analysis program. The design formulations proposed in the present paper take account of the axial compression in stiffeners caused by tension field action and external forces, the transverse forces on the stiffeners required to enforce effective division of the web plate into plate panels, and the tendency for the stiffened plate to buckle overall. The stiffener axial forces and the transverse forces due to panel bending effects were discussed in detail in previous papers $[10,11]$. 


\section{Determination of Stiffener Forces}

The components of the stiffener forces to be included in the proposed design model have been studied separately in Ref. [5] and the previous papers [10, 11], and corresponding predictive formulae have been developed. This section proposes a method for predicting the total stiffener forces that take account of the combination of the different effects.

\subsection{Axial Force In Stiffeners}

Using the concept of the tension field theory, with modifications that take account of stiffener compressibility and panel deflection, a simple validated method for the estimation of the stiffener axial force has been developed [10] for stiffened plates subjected to combined shear, compression and bending. The modifications are based on FE non-linear elastic buckling analyses of plates with a straight nondeflecting compressible stiffener. FE parametric studies also demonstrated that the stiffener axial force due to the effects of Poisson's ratio and the out-of-plane deflection of the panel is relatively small, and that for an applied shear stress up to the ultimate shear strength, the effect of panel plasticity on the stiffener axial force may be neglected. Also, the magnitudes of initial panel and stiffener imperfections do not significantly affect the stiffener axial force.

It is proposed [10] that for plates subjected to general combined shear, compression and bending, the axial force $\mathrm{P}_{\mathrm{s}}$ in the stiffener can be represented by the following equations:

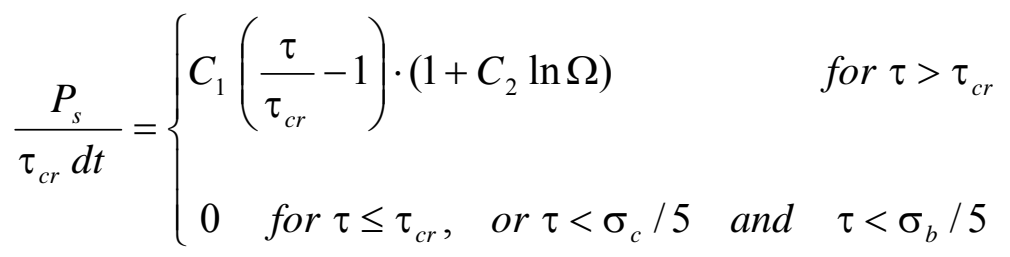

where $\Omega$ denotes the stiffener extensional rigidity ratio $\left(\Omega=\mathrm{A}_{\mathrm{s}} / \mathrm{at}\right)$, and:

$$
\begin{aligned}
& C_{1}=\frac{1}{2 \sqrt{d / a}} \\
& C_{2}=0.27+0.05 \ln (d / a)
\end{aligned}
$$


$\tau_{\text {cr }}^{0}, \sigma_{\text {crr }}^{0}$ and $\sigma_{\text {bcr }}^{0}$ are the critical stresses of the plate panel, subjected to shear, compression or bending in isolation, respectively. The stresses which produce buckling when acting in combination are denoted by $\tau_{\mathrm{cr}}, \sigma_{\mathrm{ccr}}$ and $\sigma_{\mathrm{bcr}}$. The panel dimensions are width a, depth d and thickness $\mathrm{t}$ (see Fig.1).

The critical shear stress $\tau_{\mathrm{cr}}$ in the presence of compression and bending can be calculated using Eqn. (3):

$$
\frac{\sigma_{c c r}}{\sigma_{c c r}^{0}}+\left(\frac{\sigma_{b c r}}{\sigma_{b c r}^{0}}\right)^{2}+\left(\frac{\tau_{c r}}{\tau_{c r}^{0}}\right)^{2}=1
$$

where $\tau_{\mathrm{cr}}^{0}, \sigma_{\mathrm{ccr}}^{0}$ and $\sigma_{\mathrm{b}, \mathrm{cr}}^{0}$ can be determined by the equations (4) to (6):

$$
\begin{gathered}
\tau_{c r}^{0}=k_{c r} \frac{\pi^{2} D}{d^{2} t} \quad k_{c r}=5.35+4 / \alpha^{2} \quad \alpha=\min \left(\frac{d}{a}, \frac{a}{d}\right) \geq 1 \\
\sigma_{c c r}^{0}=k_{c r} \frac{\pi^{2} D}{d^{2} t} \quad k_{c r}= \begin{cases}4 & \text { for } \quad d / a \leq 1 \\
\left(\frac{a}{d}+\frac{d}{a}\right)^{2} & \text { for } \quad d / a \geq 1\end{cases} \\
\sigma_{b c r}^{0}=k_{c r} \frac{\pi^{2} D}{d^{2} t} \quad k_{c r}= \begin{cases}24 & \text { for } \quad d / a \leq 1.5 \\
24+73\left(\frac{2}{3}-\frac{a}{d}\right)^{2} & \text { for } \quad d / a \geq 1.5\end{cases}
\end{gathered}
$$

\subsection{Bending Moment Due to Local Panel Bending Effect}

Buckled panels cause a distributed lateral force on, and bending moment in, the stiffener, which is referred to as the "panel bending effect". In the proposed design model, the bending moment in a straight rigid knife edge at the ultimate load of the plate, taking account of the effects of panel plasticity, is taken as the stiffener bending moment due to the panel bending effect, and is denoted as $\mathrm{M}_{\mathrm{pb}}$.

By comparison of the FE solutions obtained for the plate with a straight knife edge, with and without introducing plasticity of the panels, $\mathrm{Xie}([5])$ found that $\mathrm{M}_{\mathrm{pb}}$ can be estimated using:

$$
M_{p b}=F_{p l} M_{k m}
$$


where $\mathrm{M}_{\mathrm{km}}$ is the maximum knife edge moment obtained from the non-linear elastic analysis, and $\mathrm{F}_{\mathrm{pl}}$ represents the effects of panel plasticity on the knife edge moment. It was found that $\mathrm{F}_{\mathrm{pl}}$ may be approximately represented by:

$$
F_{p l}=1.6-0.35 \sqrt{\sigma_{0 p} / 355} \text { and } F_{p l} \geq 1.0
$$

Eq. (8) represents an increase in the knife edge moment due to panel plasticity as the applied shear stress approaches the ultimate shear strength, the plastic deformation in the panels increases rapidly, which in turn results in a significant increase in the panel deflection, and hence in the knife edge moment.

The calculation of the elastic knife edge moment $\mathrm{M}_{\mathrm{km}}$ is discussed in detail in Ref. [11] and summarised in the following subsections.

\subsubsection{Plates subjected to pure shear}

From the FE results of non-linear elastic buckling analyses of plates stiffened by a knife edge, it has been found [11] that for plates under pure shear the elastic knife edge moment $\mathrm{M}_{\mathrm{km}}$ can be estimated using the following equations:

$$
\begin{aligned}
& \frac{M_{k m} b}{D t}=29.71\left(\frac{w_{0 p}}{t}\right)\left(\frac{\tau}{\tau_{c r}}\right)-0.524\left(\frac{w_{0 p}}{t}\right)\left(\frac{\tau}{\tau_{c r}}\right)^{2} \\
& -6.96\left(\frac{\tau}{\tau_{c r}}\right)+4.962\left(\frac{\tau}{\tau_{c r}}\right)^{2}+21.37\left(\frac{\tau}{\tau_{c r}}\right)^{3}-2.865\left(\frac{\tau}{\tau_{c r}}\right)^{4} \\
& \frac{M_{k m} b}{D t}=83.62\left(\frac{w_{0 p}}{t}\right)\left(\frac{\tau}{\tau_{c r}}\right)-16.59\left(\frac{w_{0 p}}{t}\right)\left(\frac{\tau}{\tau_{c r}}\right)^{2} \\
& -14.03\left(\frac{\tau}{\tau_{c r}}\right)+19.70\left(\frac{\tau}{\tau_{c r}}\right)^{2}+54.99\left(\frac{\tau}{\tau_{c r}}\right)^{3}-7.676\left(\frac{\tau}{\tau_{c r}}\right)^{4} \\
& \left.\frac{M_{k m} b}{D t}=69.47\left(\frac{w_{0 p}}{t}\right)\left(\frac{\tau}{\tau_{c r}}\right)^{2}+1.942\left(\frac{w_{0 p}}{t}\right)^{2} \frac{\tau}{\tau_{c r}}\right)^{2} \\
& -16.96\left(\frac{\tau}{\tau_{c r}}\right)+80.11\left(\frac{\tau}{\tau_{c r}}\right)^{2}-7.281\left(\frac{\tau}{\tau_{c r}}\right)^{3}-0.264\left(\frac{\tau}{\tau_{c r}}\right)^{4}
\end{aligned}
$$

for $\mathrm{d} / \mathrm{a} \leq 1$ 
where $\mathrm{w}_{0 \mathrm{p}}$ is the magnitude of the initial panel imperfection (see Fig.3 of Ref. [10]). The values of $\mathrm{M}_{\mathrm{km}}$ for $1<\mathrm{d} / \mathrm{a}<2$ and $2.2<\mathrm{d} / \mathrm{a}<2.4$ can be obtained by linear interpolation.

\subsubsection{Plates subjected to combined loading}

For plates subjected to combined shear, compression and bending, it is proposed [11] that the knife edge moment $\mathrm{M}_{\mathrm{km}}$ can be estimated using Eq. (9), with $\tau / \tau_{\mathrm{cr}}$ being replaced by an equivalent shear stress ratio given by:

$$
\frac{\tau_{e q}}{\tau_{c r}^{0}}=\frac{1}{2}\left(\beta_{c} \frac{\sigma_{c}}{\sigma_{c c r}^{0}}\right)+\sqrt{\left(\frac{\tau}{\tau_{c r}^{0}}\right)^{2}+\frac{1}{4}\left(\beta_{c} \frac{\sigma_{c}}{\sigma_{c c r}^{0}}\right)^{2}+\left(\beta_{b} \frac{\sigma_{b}}{\sigma_{b c r}^{0}}\right)^{2}}
$$

By curve-fitting the FE solutions for combined loading against Eq. (9), it was found that the factor $\beta_{\mathrm{c}}$ may be taken as approximately:

$$
\begin{gathered}
\beta_{c}=\left\{\begin{array}{c}
0.45 \quad \text { for } d / a \leq 1 \text { or } d / a \geq 3 \\
0.2+0.25\left|\frac{d}{a}-2\right| \text { for } 1<d / a<3
\end{array}\right. \\
\beta_{b}=0.25
\end{gathered}
$$

Fig. 2 shows a good agreement in the knife edge moments between the FE solutions and the values calculated using the proposed equations for $\mathrm{d} / \mathrm{a}=1$ plates subjected to various stress ratios $\left(\tau / \sigma_{\mathrm{c}} / \sigma_{\mathrm{b}}\right)$.

\subsection{Bending Moment Due to Overall Buckling Effect}

Stiffened plates can buckle in two basic ways. In overall buckling, the stiffeners buckle along with the plating; in local panel buckling, the plate panels buckle between the stiffeners. For plates with elastic stiffeners subjected to shear loading, a combination of overall buckling and local panel buckling invariably occurs, as the stiffeners are unable to enforce nodal lines at the position of stiffener. For stiffened plates subjected to compression or pure bending, a stiffener rigid enough will force a nodal line forming at the position of stiffener, but the combination of overall buckling and local panel buckling can still be seen in some higher critical modes. 
The tendency for the stiffened plate to buckle overall was first studied by Stanway et al $[6,9]$ using a rigid-link model to quantify the overall buckling effect for plates under pure shear. Xie [5] presents an improved and extended study of the overall buckling behaviour, introducing a beam-plate model composed of a stiffener and two plate panels. By applying the overall buckling model for plates with an imperfect stiffener, the stiffener bending moment due to the overall buckling effect is derived by solving the eigenvalue problem formed by minimising the total potential energy of the system.

The overall buckling analyses were conducted for a wide range of stiffened plates subjected to shear, compression, bending and external force applied to one or both ends of the stiffener, respectively. The deflection functions were chosen to enable the overall buckling modes for each loading component to be represented, as shown in Table 1. For pure shear, the deflection function takes account of the inclined buckling mode.

For stiffened plates subjected to coexistent shear stress $\tau$, compressive stress $\sigma_{\mathrm{c}}$ and bending stress $\sigma_{\mathrm{b}}$, it is proposed [5] that the stiffener moment due to the overall buckling effect, denoted as $M_{o v}$, can be determined by:

$$
M_{o v}=\frac{\pi^{2} E I_{s} w_{0 s}}{d^{2}}\left(\frac{\tau / \tau_{o v}+\sigma_{c} / \sigma_{c, o v}+\sigma_{b} / \sigma_{b, o v}}{1-\tau / \tau_{o v}-\sigma_{c} / \sigma_{c, o v}-\sigma_{b} / \sigma_{b, o v}}\right)
$$

where $\mathrm{w}_{0 \mathrm{~s}}$ denotes the maximum magnitude of the initial stiffener deflection, and the overall buckling stresses for shear, compression and bending in isolation are given by, respectively:

$$
\begin{gathered}
\tau_{\text {ov }}=\frac{\pi^{2} D}{d^{2} t} \sqrt{8.155\left(\frac{d^{2}}{4 a^{2}}+\frac{4 a^{2}}{d^{2}}\right)+13.99} \cdot\left[\left(\frac{d^{2}}{4 a^{2}}+1\right)^{2}+\frac{b}{2 a} \Psi\right] /\left(\frac{d^{2}}{4 a^{2}}+1\right) \\
\sigma_{c, o v}=\frac{\pi^{2} D}{d^{2} t}\left[\left(\frac{d}{2 a}+\frac{2 a}{d}\right)^{2}+\frac{4 a b}{d^{2}} \Psi\right] \\
\sigma_{b, o v}=\frac{9 a^{2} \pi^{4} D}{2 d^{4} t} \sqrt{\left[\left(\frac{d^{2}}{4 a^{2}}+1\right)^{2}+\frac{b}{a} \Psi\right]\left[\left(\frac{d^{2}}{16 a^{2}}+1\right)^{2}+\frac{b}{a} \Psi\right]}
\end{gathered}
$$


and $\Psi$ is the stiffener flexural rigidity ratio $\left(\Psi=\mathrm{EI}_{\mathrm{s}} / \mathrm{Db}\right)$.

To include the destabilising effect of the external force $\mathrm{Q}_{1}$ applied to one end of the stiffener, it is proposed [5] that Eq. (13) should be modified as:

$$
M_{o v}=\frac{\pi^{2} E I_{s} w_{0 s}}{d^{2}}\left(\frac{\tau / \tau_{o v}+\sigma_{c} / \sigma_{c, o v}+\sigma_{b} / \sigma_{b, o v}+Q_{1} / Q_{1, o v}}{1-\tau / \tau_{o v}-\sigma_{c} / \sigma_{c, o v}-\sigma_{b} / \sigma_{b, o v}-Q_{1} / Q_{1, o v}}\right)
$$

where the $\mathrm{Q}_{1, \mathrm{ov}}$ is overall critical load for this condition, and can be expressed as:

$$
Q_{1, o v}=1.121\left[\frac{2 b}{a} \Psi+\left(\frac{d^{2}}{4 a^{2}}+1\right)^{2}+\left(\frac{d^{2}}{16 a^{2}}+1\right)^{2}\right] \frac{\pi^{2} D a}{d^{2}}
$$

For cases where the external force $\mathrm{Q}_{2}$ is applied to both ends, it is proposed that Eq. (13) should be modified as:

$$
M_{o v}=\frac{\pi^{2} E I_{s} w_{0 s}}{d^{2}}\left(\frac{\tau / \tau_{o v}+\sigma_{c} / \sigma_{c, o v}+\sigma_{b} / \sigma_{b, o v}+Q_{2} / Q_{2, o v}}{1-\tau / \tau_{o v}-\sigma_{c} / \sigma_{c, o v}-\sigma_{b} / \sigma_{b, o v}-Q_{2} / Q_{2, o v}}\right)
$$

where the overall critical load $\mathrm{Q}_{2, \mathrm{ov}}$ can be expressed as:

$$
Q_{2, o v}=\left[\frac{b}{a} \Psi+\left(\frac{d^{2}}{4 a^{2}}+1\right)^{2}\right] \frac{\pi^{2} D a}{d^{2}}
$$

\subsection{Combination of Force Components}

The interaction between the panel bending and overall buckling effects was studied by Stanway [6] for pure shear using the "rigid-link" model. The panel bending effect was incorporated in the model by applying a lateral distributed force to the stiffener, which was taken as the lateral force acting on a straight rigid knife edge. It was established that the total stiffener moment may be expressed as [9]:

$$
M_{s}=M_{o v}+\frac{M_{p b}}{1-\tau / \tau_{o v}}
$$


It is noted that the second term on the right-hand side of Eq. (21) is a conservative approximation. Further, for an adequate stiffener, the ratio of $\tau / \tau_{\mathrm{ov}}$ is much less than 1.0 . Therefore, it is reasonable to simplify Eq. (21) as:

$$
M_{s}=M_{o v}+M_{p b}
$$

According to Eq. (22), the total stiffener bending moment $\mathrm{M}_{\mathrm{s}}$ can be approximately calculated simply by adding the components of stiffener moment due to the local panel bending effect and the tendency for the stiffened plate to buckle overall. Such a simplification is especially useful for the combined loading conditions, where the interaction is much more complicated.

Based on the above discussion, it is proposed that the stiffener should be designed to resist the coexistent bending moment $\mathrm{M}_{\mathrm{s}}$ and axial force $\mathrm{P}_{\mathrm{s}}$, with the stiffener cross-section consisting of the actual stiffener area only. It is reiterated that the axial force $\mathrm{P}_{\mathrm{s}}$ is determined using Eq. (1), while the stiffener bending moment $M_{s}$ is calculated using Eq. (22), where $M_{p b}$ and $M_{o v}$ are given in Eqs (7) and (13), respectively.

In Fig. 3, the elastic stiffener moment (i.e., $\mathrm{M}_{\mathrm{s}}=\mathrm{M}_{\mathrm{pk}}+\mathrm{M}_{\mathrm{ov}}$ ), estimated using the proposed method but taking the panel plasticity factor $\mathrm{F}_{\mathrm{pl}}=1$, is compared with the finite element solutions.

It should also be pointed out that the proposed method for predicting the stiffener forces is developed for stiffeners whose sizes are within the practical range; that is, the stiffener should be large enough to effectively divide the plate. For a weak stiffener, the knife edge model is not valid, and neither is the equation for estimating the bending moment due to the overall buckling effect. This is because the bending moment due to the overall buckling effect is derived from the overall buckling model by assuming that the applied stress is much less than the overall buckling stress. However, for a weak stiffener, this may not be true.

\section{Design Criteria for Stiffeners}

Transverse stiffeners are introduced mainly to increase the plate strength, but they also help to achieve the intended geometry of the girder section. An adequate stiffener should satisfy the following requirements: 
(1) The chosen stiffener should enable the ultimate strength of the stiffened plate to be at least equal to the strength of the individual panel, assuming it is simply supported. The minimum flexural rigidity which satisfies this criterion will be denoted as $\Psi_{\text {ssu. }}$.

(2) The chosen stiffener should effectively divide the plating; that is, an effectively divided panel deflection mode should be maintained until the ultimate load of the stiffened plate is reached.

(3) The chosen stiffener should not be unnecessarily large. The stiffener size adopted should ideally be such that a further significant increase in the stiffener size results in only a very small relative increase in the ultimate strength, while a significant reduction in the stiffener size results in a significant reduction in the ultimate strength.

(4) The chosen stiffener should prevent a rapid reduction in the load carrying capacity of the stiffened plate in the post-ultimate region. It is therefore desirable that stiffener failure does not occur before panel failure: it is assumed that this will be achieved if the stiffener does not yield at the maximum resistance of the stiffened plate.

In this section, strength and stiffness requirements are introduced to size the stiffener. Attention is paid mainly to double-sided stiffeners, while special considerations required for single-sided stiffeners are presented in Subsection 3.3.

\subsection{Strength Criterion}

\subsubsection{Calculation of Stiffener Stresses}

As stated in Section 2.4, in the proposed design model, a stiffener is assumed to be subjected to the coexistent bending moment $\mathrm{M}_{\mathrm{s}}$ and axial force $\mathrm{P}_{\mathrm{s}}$, with the stiffener cross-section consisting of the actual stiffener area $A_{s}$ only. It is noted that the predictive formulae for the axial force in the stiffener are developed from the non-deflecting stiffened plate model, in which the stiffener is modelled using truss elements which lie in the mid-plane of the plate. Therefore, the axial force $\mathrm{P}_{\mathrm{s}}$ should be taken as acting in the mid-plane of the plate, as illustrated in Fig. 4.

For double-sided flat bar stiffeners, the stiffener area $A_{s}$ and the moment of inertia $I_{s}$ are calculated as follows:

$$
A_{s}=2 h_{s} t_{s}
$$




$$
I_{s}=\frac{1}{12} t_{s}\left[\left(2 h_{s}+t\right)^{3}-t^{3}\right]
$$

The definitions of $h, h_{s}$ and $t_{s}$ are illustrated in Fig. 1. For single-sided flat bar stiffeners, the stiffener area $A_{s}$ and the moment of inertia $I_{s}$ are taken as:

$$
\begin{gathered}
A_{s}=h_{s} t_{s} \\
I_{s}=\frac{1}{12} t_{s} h_{s}^{3}
\end{gathered}
$$

It is indicated in Fig. 4 that for double-sided stiffeners, the stiffener can be designed as a simple beam loaded by an axial force equal to $\mathrm{P}_{\mathrm{s}}$ acting at the centroid of the stiffener cross-section, and a bending moment $\mathrm{M}_{\mathrm{s}}$ about the centroidal axis 1-1. For single-sided flat bar stiffeners, the stiffener can be designed as a simple beam loaded by a bending moment $\mathrm{M}_{\mathrm{s}}$ and an eccentric axial load $\mathrm{P}_{\mathrm{s}}$ acting at a distance $\left(\mathrm{h}_{\mathrm{s}}+\mathrm{t}\right) / 2$ from the centroidal axis $1-1$ of the stiffener cross-section. It is apparent that for the single-sided stiffener, an additional bending moment resulting from the eccentricity of the axial load $\mathrm{P}_{\mathrm{s}}$ should be included, and the two possible combinations of the stiffener forces should be considered for the design of the eccentric stiffener.

It is proposed that for double-sided (concentric) stiffeners, the maximum stress in the stiffener can be calculated as follows:

$$
\sigma_{s, \max }=\frac{P_{s}}{A_{s}}+\frac{M_{s}}{Z_{s}}
$$

For load bearing stiffeners, the stiffener axial force $\mathrm{P}_{\mathrm{s}}$ in Eq. (27) should be replaced with the total axial force $\mathrm{P}_{\mathrm{s}, \text { total }}$, which is proposed to be as follows:

$$
P_{s, \text { total }}=P_{s}+Q_{1}, \quad \text { or } \quad P_{s}+Q_{2}
$$

where $\mathrm{Q}_{1}$ and $\mathrm{Q}_{2}$ are the external stiffener forces acting at one end and at both ends, respectively. A more detailed discussion on load bearing stiffeners is presented in Section 4.2. As required in the design codes [2-4], a bearing stiffener should be double-sided and symmetric about the mid-plane of the plate.

\subsubsection{Strength Requirement}


The purpose of the strength requirement is to ensure that stiffener failure does not occur before panel failure. This is necessary because otherwise the stiffener deflection might be such that the panel strength would not be mobilized, and because stiffener failure causes a rapid reduction in resistance of the stiffened plate.

Stiffener failure may be prevented in design by providing a stiffener for which the yield stress is not exceeded, referred to as "the no yield criterion". The no yield criterion has been adopted in the design methods proposed by Stanway et al [9], and by Rahal and Harding [8]. Another criterion, as adopted in the method by Rockey et al [12], is to provide a stiffener for which the plastic moment capacity is not exceeded, referred to as "plastic collapse criterion". It is noted that after yielding, the stiffener stiffness will diminish, the deflection will increase, and the analytical assumptions may be violated.

For the strength design of the transverse stiffener, the no yield criterion is adopted here. It is proposed that the maximum stress in the stiffener, calculated using Eq. (27), should not exceed the yield stress of the stiffener; that is:

$$
\sigma_{s, \max } \leq \sigma_{0 s}
$$

For design of the stiffener the ultimate load for a simply supported panel is taken as the load applied on the stiffened plate. However, the actual plate strength is often greater than the strength for the simply supported panel, and therefore it is desirable that the required stiffener size according to the strength criterion would ensure the stiffener remains elastic at the actual ultimate load of the stiffened plate, and this condition is checked against the FE results in the section below.

\subsubsection{Required Stiffeners according to the Strength Criterion}

In order to show to what extent the forces given by the proposed method result in a stiffener which satisfies the strength criterion, the flexural rigidity of the smallest stiffener (double-sided, $h / t_{s}=10$ ) which satisfies the strength criterion of Eq. (29), denoted as $\Psi_{\mathrm{dZ}}$, is compared with the ultimate strength results from the non-linear elasto-plastic FE analyses. The applied load was taken as the ultimate load of the simply supported panel obtained from FE analysis, as given in Ref. [5]. Stiffener sizes for plates under different loading conditions were determined. 


\section{- $\quad$ Plates subjected to pure shear}

In Ref [5], the FE $\tau_{\mathrm{u}}$ ' vs. $\Psi$ results given by Fortune [13] are used to validate the required stiffener size $\Psi_{\mathrm{dZ}}$ calculated according to the proposed method for a range of cases with $\mathrm{d} / \mathrm{a}=0.5$ to 7 and $\mathrm{b} / \mathrm{t}=80$ to 180 . As an illustration, Fig. 5 presents the comparisons made for $\mathrm{b} / \mathrm{t}=180$ and $\mathrm{d} / \mathrm{a}=1$ and 2 , with the yield stress of stiffener and panel material being $245 \mathrm{~N} / \mathrm{mm}^{2}$. Also included in Fig.5 is the flexural rigidity of the smallest stiffener (double-sided, $\mathrm{h} / \mathrm{t}_{\mathrm{s}}=10$ ) which satisfies the stiffness criterion (Section 3.2 ), denoted as $\Psi_{\text {dI }}$

According to the strength criterion, the stiffener with a rigidity of $\Psi_{\mathrm{dz}}$ should remain elastic at the ultimate load of the plate. This is indicated by the position of $\Psi_{\mathrm{dZ}}$ in relation to $\Psi_{\mathrm{p}}$ (the largest value of $\Psi$, of those considered, for which yielding of the stiffener occurs at the ultimate load) and $\Psi_{\mathrm{e}}$ (the smallest value of $\Psi$, of those considered, for which yielding of the stiffener does not occur at the ultimate load). The value of $\Psi$ for which the stiffener just remains elastic at the ultimate load lies between $\Psi_{\mathrm{p}}$ and $\Psi_{\mathrm{e}}$.

It was found that for all the cases examined by Xie [5], the required stiffener rigidity $\Psi_{\mathrm{dz}}$ is in close proximity to the region bounded by $\Psi_{\mathrm{p}}$ and $\Psi_{\mathrm{e}}$, and mostly greater than $\Psi_{\mathrm{p}}$. The implication of this observation is that the stiffener forces determined in accordance with the proposed method are satisfactory.

For a stiffener design model, the basic requirement is that it should provide a stiffener which will ensure that the ultimate load for the stiffened plate is at least as great as the ultimate load for the simply supported panel. The minimum flexural rigidity which satisfies this criterion is denoted as $\Psi_{\text {ssu }}$. In Fig. 5, $\Psi_{\text {ssu }}$ is also indicated on the $\tau_{\mathrm{u}}$ ' vs. $\Psi$ results curves. For the calculation of $\Psi_{\mathrm{dZ}}$ to be satisfactory in sizing the required stiffener, it should be equal to or greater than $\Psi_{\text {ssu; }}$; that is:

$$
\Psi_{d Z} \geq \Psi_{s s u}
$$

It has been observed in Ref. [5] that the required stiffener rigidity $\Psi_{\mathrm{dZ}}$ is in close proximity to $\Psi_{\text {ssu }}$, and in most of the cases, is equal to or greater than $\Psi_{\text {ssu }}$. For $\mathrm{d} / \mathrm{a}=0.5, \mathrm{~b} / \mathrm{t}=180$, it is found that the ultimate strength of the stiffened plates is negligibly less than the panel strength (about $0.5 \%$ ), even for a stiffener 
of great rigidity $\Psi$. However, the design stiffener $\Psi_{\mathrm{dz}}$ for this case is considered to be adequate, because any increase in $\Psi$ from $\Psi_{\mathrm{dz}}$ will not result in appreciable increase in $\tau_{\mathrm{u}}{ }^{\prime}$ for the stiffened plate. It was noted that for $\mathrm{d} / \mathrm{a}=0.5$ and 1 , the region bounded by $\Psi_{\mathrm{p}}$ and $\Psi_{\mathrm{e}}$ is at a significant distance along the plateau of the $\tau_{\mathrm{u}}{ }^{\prime}$ vs. $\Psi$ curve, and this means that a stiffener which just remains elastic at the ultimate load will represent the required stiffener size.

However, for $\mathrm{d} / \mathrm{a} \geq 2$, although the stiffener rigidity $\Psi_{\mathrm{d} Z}$ is satisfactory according to the proposed strength criterion, it was observed that it is not on the plateau of the $\tau_{\mathrm{u}}{ }^{\prime}$ vs. $\Psi$ curve, and therefore cannot be taken as an adequate stiffener. It is noted that for these cases, the stiffener which remains fully elastic at the ultimate load is relatively small compared to the required stiffener sizes, and deflects to a degree which would not provide adequate subdivision of the plate, and would result in a reduction in the plate resistance. For this reason, a stiffness criterion is also necessary to ensure that the design stiffener is adequate, and the stiffness criterion is presented in Section 3.2.

\section{- Plates subjected to combined loading}

The proposed design method is based on theoretical solutions and extensive numerical results, and has been verified at each stage of model development. Therefore, only a group of typical cases were analysed to provide a basis for the validation of the proposed design model when used for the combined loading conditions. The plates of $\mathrm{d} / \mathrm{a}=2$ and $\mathrm{b} / \mathrm{t}=180$ were considered, and the ratios of individual loading components examined are: $\sigma_{\mathrm{c}}: \tau=1: 0,1: 2,1: 5$ for shear and compression, and $\sigma_{\mathrm{b}}: \tau=1: 0,2: 1,1: 1$ for shear and bending. These cases were chosen to cover the limiting loading conditions (i.e., longitudinal compression or bending alone) and the conditions with which the possible maximum errors in estimating the knife edge moment according to the proposed method may be associated.

In Fig. 6, the required stiffener size $\Psi_{\mathrm{dz}}$ according to the proposed strength criterion is compared with the ultimate strength results from FE analyses (more comparisons for other stress ratios were given in Ref. [5]). It was found that for the shear and compression cases considered, the ultimate load corresponding to the stiffener rigidity $\Psi_{\mathrm{d} z}$ is well above the ultimate load of the simply supported panel, that is, the requirement given in Eq. (30) is satisfied. For the combined shear and bending cases examined, it was 
found that the ultimate load for the stiffened plate is slightly lower (about $2 \%$ ) than the ultimate load for the simply supported individual panel.

It was observed that the required stiffener rigidity $\Psi_{\mathrm{dZ}}$ is within or beyond the region bounded by $\Psi_{\mathrm{p}}$ and $\Psi_{\mathrm{e}}$, that is, the stiffener determined in accordance with the proposed strength criterion will remain elastic at the ultimate load. However, it was observed [5] that the stiffener having a rigidity of $\Psi_{\mathrm{d} Z}$ does not always effectively divide the plate into panels, which further demonstrates the necessity of introducing a stiffness criterion.

\subsection{Stiffness Criterion}

\subsubsection{Calculation of Stiffener Deflection}

For stiffened plates subjected to pure shear, it has been found that the stiffener deflection may be closely represented by a half sine wave [6,9], and this shape has been assumed for stiffness design of the stiffener. This assumption is also consistent with that made in the overall buckling model (Section 2.3), from which the stiffener moment due to the overall buckling effect is derived.

As implied in the "no yield" strength criterion, the stiffener is considered to be elastic in the proposed design model. Therefore, using the half sine wave assumption, the stiffener deflection $\mathrm{w}_{\mathrm{s}}$ can be written as:

$$
w_{s}=\frac{M_{s} d^{2}}{\pi^{2} E I_{s}}
$$

where $\mathrm{w}_{\mathrm{s}}$ and $\mathrm{M}_{\mathrm{s}}$ are the maximum values along the stiffener length, and the stiffener moment $\mathrm{M}_{\mathrm{s}}$ is given by Eq. (22).

In Fig. 7, the stiffener deflection given by Eq. (31) is compared with the FE solutions. The point corresponding to the ultimate load is indicated on the elasto-plastic $\mathrm{w}_{\mathrm{s}} / \mathrm{t} v \mathrm{vs} \mathrm{M}_{\mathrm{s}} / \mathrm{M}_{\mathrm{ps}}$ curve. It can be observed that the variation in $\mathrm{w}_{\mathrm{s}}$ with $\mathrm{M}_{\mathrm{s}}$ is basically linear, which would be expected if the half sine wave prevails, especially prior to the ultimate load, and the agreement between Eq. (31) and the FE results is considered to be satisfactory. Similar comparisons were made by Stanway [6] for different 
values of $\Psi$. In the design model by Stanway et al [9], the stiffener deflection is also estimated by means of Eq. (22).

\subsubsection{Design Limit on Stiffener Deflection}

For plates subjected to pure shear, it was found by Stanway et al [9] that if the stiffener effectively divides the plate, then a plate strength within the plateau of the $\tau_{\mathrm{u}}{ }^{\prime}$ vs. $\Psi$ curve, and greater than that for simply supported panels, will be attained. To ensure that the plate is effectively divided, the deflection of the stiffener at the ultimate load, denoted as $\mathrm{w}_{\mathrm{su}}$, must be sufficiently small. The approach adopted in the proposed design model is therefore to specify a maximum allowable stiffener deflection which will ensure that the plate is effectively divided, and hence that the plate strength is within the plateau of the strength against $\Psi$ curve.

The stiffness criterion originally developed by Stanway et al [9] is that the stiffener deflection measured over a panel buckle half wavelength should be small in relation to the amplitude of the panel buckle for a rigid stiffener, and the panel deflection is assumed to be that given by non-linear elastic analyses for a simply supported panel. This approach is logical in that it introduces a quantitative means to define the subdivision of the plate. However, it involves the estimation of the panel deflection, which has been found to be quite complicated even for pure shear, due to the variation of the deflection mode with the applied load. For plates subjected to combined shear and longitudinal loading, the estimation of the panel deflection will be much more difficult.

An alternative approach to ensure the subdivision of the plate is to limit the out-of-straightness of the stiffener. Assuming that the deflected shape of the stiffener is a half sine wave, the out-of-straightness of the stiffener may be represented by the ratio of $\mathrm{w}_{\mathrm{s}} / \mathrm{d}$.

The stiffener deflection ratio $\mathrm{w}_{\mathrm{s}} / \mathrm{d}$ must be small enough to ensure that the effectively divided panel mode and the required plate strength are achieved. For plates subjected to pure shear, this means that a plate strength within the plateau of the $\tau_{\mathrm{u}}{ }^{\prime}$ vs. $\Psi$ curve should be attained. In order to define consistently a point of reference for the start of the plateau, the following parameter is introduced: 


$$
\mu_{u}=\frac{\tau_{u}(\Psi)-\tau_{u}(\Psi=0)}{\tau_{u}\left(\Psi=\Psi_{\max }\right)-\tau_{u}(\Psi=0)}
$$

where $\Psi_{\max }$ denotes the maximum finite stiffener rigidity considered in the parametric analyses.

Fig. 8 presents the $\mu_{\mathrm{u}}$ vs. $\mathrm{d} / \mathrm{w}_{\mathrm{su}}$ results derived from the FE solutions given by Fortune [13] for plates subjected to pure shear. Marked on the $\mu_{\mathrm{u}} \mathrm{vs.} \mathrm{d} / \mathrm{w}_{\mathrm{su}}$ curves are the positions for $\mu_{\mathrm{u}}=0.95$. It can be seen that $d / w_{\text {su }}$ for $\mu_{\mathrm{u}}=0.95$ remains at the start of the plateau of the $\mu_{\mathrm{u}} \mathrm{vs.} \mathrm{d} / \mathrm{w}_{\mathrm{su}}$ curve. Similar results are also found for other $\mathrm{d} / \mathrm{a}$ and $\mathrm{b} / \mathrm{t}$ ratios.

The values of $\mathrm{d} / \mathrm{w}_{\mathrm{su}}$ corresponding to $\mu_{\mathrm{u}}=0.95$, interpolated from the FE results, are shown against the panel aspect ratio $\mathrm{d} / \mathrm{a}$ in Fig. 9, where it is noted that a single value of the limit of $\mathrm{d} / \mathrm{w}_{\mathrm{su}}$ may be specified for a given $\mathrm{d} / \mathrm{a}$ and different values of $\mathrm{b} / \mathrm{t}$.

For design of transverse stiffeners, it is proposed that the stiffener deflection at the ultimate load, $\mathrm{w}_{\mathrm{su}}$, calculated using Eq. (31), should be less than the design limit of the stiffener deflection, denoted as $\mathrm{w}_{\mathrm{sd}}$, that is:

$$
w_{s u} \leq w_{s d}
$$

where $\mathrm{w}_{\mathrm{sd}}$ for double-sided (concentric) stiffeners is given by:

$$
\frac{w_{s d}}{d}= \begin{cases}\frac{1}{500}\left(\frac{b}{d}\right), & \text { for } \frac{d}{a} \leq 2 \\ \frac{1}{4000}\left(7-6 \frac{a}{d}\right), & \text { for } 2<\frac{d}{a}<3 \\ \frac{1}{800}, & \text { for } \frac{d}{a} \geq 3\end{cases}
$$

The proposed design limit of $\mathrm{w}_{\mathrm{su}} / \mathrm{d}$ given by Eq. (34) is also shown in Fig. 9. It is noted that for $\mathrm{d} / \mathrm{a}=2$, $\mathrm{b} / \mathrm{t}=80$, the proposed value $\left(\mathrm{w}_{\mathrm{su}} / \mathrm{d}=1 / 1000\right)$ is less than that for $\mu_{\mathrm{u}}=0.95$. Nevertheless, it was found in Ref. [5] that a plate strength within the plateau of the $\mu_{\mathrm{u}} \mathrm{vs.} d / \mathrm{w}_{\mathrm{su}}$ curve can still be achieved for $\mathrm{w}_{\mathrm{su}} / \mathrm{d}=1 / 1000$. 
In Fig 5, the stiffener rigidity for which the stiffener deflection at the ultimate load is equal to the deflection limit specified in Eq. (34), denoted as $\Psi_{\mathrm{w}}$, is also indicated. The value of $\Psi_{\mathrm{w}}$ is estimated by the interpolation of the finite element solutions. It can be seen in Fig. 5 that $\Psi_{\mathrm{w}}$ lies within the plateau of the $\tau_{\mathrm{u}}{ }^{\prime}$ vs. $\Psi$ curve. It should be noted that $\Psi_{\mathrm{w}}$ is from finite element solutions, not from the design model.

It is also proposed that the design limit of $\mathrm{w}_{\mathrm{su}} / \mathrm{d}$ given by Eq. (34) is valid for plates subjected to combined shear and longitudinal loading, because the ratio of $\mathrm{w}_{\mathrm{su}} / \mathrm{d}$ specified in Eq. (34) represents the requirement of the stiffener straightness for the effective subdivision of the plate for double-sided stiffeners.

\subsubsection{Required Stiffener Size According to the Stiffness Criterion}

In this section, the flexural rigidity of the smallest stiffener (double-sided, $h / t_{s}=10$ ) which satisfies the proposed stiffness criterion in Eqs. (33) and (34), denoted as $\Psi_{\mathrm{d} \text {, }}$, is compared with the ultimate strength results from the non-linear elasto-plastic FE analyses. The stiffener moment $\mathrm{M}_{\mathrm{s}}$ was calculated using Eq. (22). The applied load was taken as the ultimate load of the simply supported panel, and stiffener sizes for plates under different loading conditions were determined.

\section{- Plates subjected to pure shear}

The comparisons of the required stiffener flexural rigidity $\Psi_{\mathrm{dI}}$ with the FE results of the ultimate shear stress ratio $\tau_{\mathrm{u}}{ }^{\prime}$ vs. $\Psi$ are presented in Fig. 5 for plates subjected to pure shear for $\mathrm{b} / \mathrm{t}=180$ and $\mathrm{d} / \mathrm{a}=1$ and 2 , where the smallest stiffener which satisfies the strength criterion, $\Psi_{\mathrm{dZ}}$, is also included. A more extensive comparison is given in Ref. [5]. It was found that for the cases considered, the stiffener with a rigidity of $\Psi_{\mathrm{dI}}$, determined in accordance with the proposed stiffness criterion, can ensure that the plate is effectively divided, and consequently a plate strength within the plateau of the $\tau_{\mathrm{u}}{ }^{\prime}$ vs. $\Psi$ curve, and greater than the strength for simply supported panels, is attained.

By comparison of the required stiffener rigidities $\Psi_{\mathrm{dZ}}$ and $\Psi_{\mathrm{d}}$, it was found in Ref. [5] that for the cases examined for $\mathrm{d} / \mathrm{a}=0.5$ and 1 , the adequate design size of the stiffener, denoted as $\Psi_{\mathrm{d}}\left(\Psi_{\mathrm{d}}=\max \left\{\Psi_{\mathrm{dZ}}, \Psi_{\mathrm{dl}}\right\}\right)$, 
is governed by the strength criterion, whereas for all the other cases, the stiffness criterion governs. It was also observed that the design stiffener rigidity $\Psi_{\mathrm{d}}$ is in general at a satisfactory distance along the plateau of the $\tau_{\mathrm{u}}{ }^{\prime}$ vs. $\Psi$ curve.

The above observation suggests that in order to provide an adequate stiffener design, both the strength and stiffness criteria are required. The two criteria are necessary when considering the possible combinations of stiffener properties. For example, if the ratio $Z_{s} / I_{s}$ is increased, or if the yield stress of stiffener is increased, the strength criterion is more likely to produce an unsatisfactory stiffener. On the other hand, if the ratio $Z_{\mathrm{s}} / I_{\mathrm{s}}$ is reduced, for example, by replacing a flat bar stiffener with a Tee stiffener, the stiffness criterion is more likely to result in an unsatisfactory stiffener. In the proposed design model, both the strength and stiffness criteria are used to quantify the required stiffener.

\section{- $\quad$ Plates subjected to combined loading}

In Fig. 6, the required stiffener size $\Psi_{\mathrm{dI}}$ according to the proposed stiffness criterion is compared with the ultimate strength results from FE analyses for the cases discussed in Section 3.1.3. It is apparent that for the cases considered, for the required stiffener $\Psi_{\mathrm{d}}$, the plate strength is within the plateau region of the strength curve, and is very close to or greater than the strength for simply supported panels.

It was found in Ref. [5] that for the cases examined for combined loading, the design size of the stiffener $\Psi_{\mathrm{d}}$ is governed by the stiffness criterion, and $\Psi_{\mathrm{d}}$ is at a reasonable distance along the plateau of the strength curve. By examining the contour plots of the out-of-plane deflection at the ultimate load, it was seen that for the stiffener rigidity $\Psi_{\mathrm{d} \text {, }}$, an effectively divided panel mode is achieved ([5]).

In Table 2, the numerical values of $\Psi_{\mathrm{dz}}$ and $\Psi_{\mathrm{dI}}$ required for the combined loading are compared with those for pure shear. It is observed that for the same stiffener type, the design stiffener rigidity $\Psi_{d}$ for the combined loading conditions may be considerably less than that required for the same plate to achieve its pure shear strength. This suggests that it would be considerably conservative if the stiffener designed to develop the maximum shear capacity of the panel is used for other combinations of shear and compression. 


\subsection{Design of Single-Sided Stiffeners}

For single-sided stiffeners, a variety of assumptions in respect of the neutral axis and the effective section of the stiffener are made in existing design methods. According to BS5400 [2] and Eurocode 3 [3], the effective cross-section of the stiffener consists of stiffener section itself and a width of plate. In some other methods, as that proposed by Horne and Grayson [14], only the actual stiffener section is considered, but the neutral axis of the stiffener section is taken to be at the surface of the plate. They suggested that with the moment of inertia $\mathrm{I}_{\mathrm{s}}$ calculated about an axis at the surface of the plate, the singlesided stiffener can be designed to achieve the same flexural rigidity $\Psi$ as required for double-sided stiffeners.

In this section, based on the numerical results for plates with a single-sided flat bar stiffener $\left(h_{s} / t_{s}=10\right)$, a method for calculating the stresses in the single-sided stiffener is proposed. Special design requirements for single-sided stiffeners are discussed.

\subsubsection{Calculation of Stiffener Stress}

It has been pointed out in Section 3.1.1 that a single-sided stiffener is to be designed as a simple beam loaded by a bending moment $\mathrm{M}_{\mathrm{s}}$ (from the lateral distributed force) and an eccentric axial load $\mathrm{P}_{\mathrm{s}}$ acting at a distance e, $e=\left(h_{s}+t\right) / 2$ for flat bar stiffeners, from the centroidal axis 1-1 (Fig. 4) of the stiffener cross-section (Fig. 1). The eccentric load $P_{s}$ is statically equivalent to a force $P_{s}$ applied at the centroid plus a couple equal to $P_{s} \cdot e$. To calculate the maximum stress in the stiffener, the two possible combinations of the stiffener forces should be considered for the design of the eccentric stiffener. It is recalled that according to the proposed design model, the stiffener cross-section consists of the actual stiffener section only.

An adequate stiffener should be rigid enough to divide the plate, and the axial force in such a stiffener is always a compressive force as given in Eq. (1). In Fig. 10, two possible combinations of the axial force $P_{s}$ and the bending moment $M_{s}$ are illustrated. For the case 1 (Fig. 10a), where the tip of the stiffener is in compression, the stiffener forces with respect to the centroidal axis $1-1$ are given by: 


$$
P_{s, 1}=P_{s}, \quad M_{s, 1}=M_{s}-P_{s} \cdot e
$$

and the maximum compressive and tensile stresses can be calculated by:

$$
\begin{gathered}
\sigma_{s, C}=\frac{P_{s}}{A_{s}}+\frac{\left(M_{s}-P_{s} \cdot e\right)}{Z_{s, C}} \\
\sigma_{s, T}=-\frac{P_{s}}{A_{s}}+\frac{\left(M_{s}-P_{s} \cdot e\right)}{Z_{s, T}}
\end{gathered}
$$

where $Z_{\mathrm{s}, \mathrm{C}}$ and $Z_{\mathrm{s}, \mathrm{T}}$ are the section moduli for the compressive and tensile edges of the stiffener, respectively.

For the case 2 (Fig. 10b), where the tip of the stiffener may be in tension, the stiffener forces with respect to the centroidal axis $1-1$ can be written as:

$$
P_{s, 1}=P_{s}, \quad M_{s, 1}=M_{s}+P_{s} \cdot e
$$

and the maximum compressive and tensile stresses can be calculated by:

$$
\begin{gathered}
\sigma_{s, C}=\frac{P_{s}}{A_{s}}+\frac{\left(M_{s}+P_{s} \cdot e\right)}{Z_{s, C}} \\
\sigma_{s, T}=-\frac{P_{s}}{A_{s}}+\frac{\left(M_{s}+P_{s} \cdot e\right)}{Z_{s, T}}
\end{gathered}
$$

The FE solutions presented by Xie [5] demonstrate that for plates of $d / a=2$, the stress at the tip of the stiffener is always more compressive than at the plate edge at the ultimate load, while for plates of $d / a=5$ the tip of the stiffener is in tension, and the edge in contact with the plate is in compression. It is also noted that the stiffener bending moment $\mathrm{M}_{\mathrm{s}, 1}$ in case 2 is greater than that in case 1 (Fig. 10).

In view of the above discussion, it is suggested that for the calculation of the maximum stresses in the single-sided stiffener, Eqs. (35) to (37) should be used for plates of $d / a \leq 2$, while for plates of $d / a>2$, Eqs. (38) to (40) should be used. It should be pointed out that this suggestion is based on a small number of cases, and it is necessary that further verification should be made over a wide range of $\mathrm{d} / \mathrm{a}$ and $\mathrm{b} / \mathrm{t}$.

\subsubsection{Stiffener Deflection and Its Design Limit}


For single-sided stiffeners, the stiffener deflection can still be estimated using Eqn. (31), which is derived from simple beam theory by assuming that the stiffener deflects in a half sine wave. The moment of inertia of the stiffener section $\mathrm{I}_{\mathrm{s}}$ should be taken about the centroidal axis of the stiffener section. For flat bar stiffeners, $I_{s}$ is given by Eq. (26).

The bending moment $\mathrm{M}_{\mathrm{s}}$ in Eq. (31) should be replaced with the moment about the centroidal axis 1-1 of the stiffener section, $M_{s, 1}$. It is proposed in Section 3.3.2 that for $d / a \leq 2, M_{s, 1}$ is given by Eq. (35), while for $\mathrm{d} / \mathrm{a}>2, \mathrm{M}_{\mathrm{s}, 1}$ is given by Eq. (38).

Fig. 11 presents the $\tau_{\mathrm{u}}$ vs. $\mathrm{d} / \mathrm{w}_{\mathrm{su}}$ curves obtained from the FE analyses carried out for plates of $\mathrm{d} / \mathrm{a}=2,5$ and $\mathrm{b} / \mathrm{t}=180$, with a single-sided flat bar stiffener $\left(\mathrm{h}_{\mathrm{s}} / \mathrm{t}_{\mathrm{s}}=10\right)$ of varying flexural rigidity $\Psi$, subjected to pure shear. It is observed that by taking $\mathrm{d} / \mathrm{w}_{\mathrm{su}}=500$ for $\mathrm{d} / \mathrm{a}=2$ and 400 for $\mathrm{d} / \mathrm{a}=5$ respectively, the required plate strength can be achieved. It is noted that these two values of $\mathrm{d} / \mathrm{w}_{\mathrm{su}}$ are equal to the twice the limit specified in Eq. (34).

For design of single-sided stiffeners, it is thus proposed that the design limit of the stiffener deflection, $\mathrm{W}_{\text {sd }}$, can be taken as the twice the value proposed for the double-sided stiffeners (Eq. 34). That is, the value of $\mathrm{w}_{\mathrm{sd}}$ for the single-sided stiffener can be expressed as:

$$
\frac{w_{s d}}{d}= \begin{cases}\frac{1}{250}\left(\frac{b}{d}\right), & \text { for } \frac{d}{a} \leq 2 \\ \frac{1}{2000}\left(7-6 \frac{a}{d}\right), & \text { for } 2<\frac{d}{a}<3 \\ \frac{1}{400}, & \text { for } \frac{d}{a} \geq 3\end{cases}
$$

As for the suggestions made in Section 3.3.1, it is recognised that Eq. (41) is also based on a small number of cases, and further verification over a wide range of $d / a$ and $b / t$ is needed.

\subsubsection{Required Stiffener Size}


Plates subjected to pure shear are considered in this section. Table 3 presents the smallest stiffeners (single-sided, $h_{s} / t_{s}=10$ ) which satisfy the proposed strength criterion (Eq. 29) and the stiffness criterion (Eq. 33), represented by $\Psi_{\mathrm{dZ}}$ and $\Psi_{\mathrm{dI}}$ respectively. In Fig. 12, $\Psi_{\mathrm{dz}}$ and $\Psi_{\mathrm{dI}}$ are compared with the finite element results of $\tau_{\mathrm{u}}{ }^{\prime}$ vs. $\Psi$. It is reiterated that for design of the stiffener, the applied load was taken as the ultimate load of the simply supported panel.

It can be observed in Fig. 12 that the required stiffener rigidity $\Psi_{\mathrm{d} Z}$ is greater than $\Psi_{\mathrm{e}}$ for both cases considered, which implies that the stiffener of rigidity $\Psi_{\mathrm{dz}}$ does not yield at the ultimate load. It is also seen that the required stiffener $\Psi_{\mathrm{d} Z}$ can ensure the plate strength to be greater or nearly equal to the panel strength. It is noted that for $\mathrm{d} / \mathrm{a}=2, \Psi_{\mathrm{dz}}$ is smaller than $\Psi_{\text {ssu }}$, but the difference in the plate strengths for the two stiffener rigidities is negligible. However, by reference to the contour diagrams of the deflection modes at the ultimate load, it was found that the required stiffener according to the strength criterion, $\Psi_{\mathrm{dz}}$, does not produce an effectively divided panel mode (Ref. [5]).

As for the required stiffener in accordance with the stiffness criterion, it is apparent in Fig. 12 that the stiffener with a rigidity of $\Psi_{\mathrm{dI}}$ can ensure that the plate strength lies within the plateau of the $\tau_{\mathrm{u}}{ }^{\prime}$ vs. $\Psi$ curve, and is greater than the strength for simply supported panels. By referring to the contour plots, it was observed that the stiffener with a rigidity of $\Psi_{\mathrm{dI}}$ results in an effectively divided panel mode [5].

The design size of the stiffener is again taken as $\Psi_{\mathrm{d}}=\max \left\{\Psi_{\mathrm{dz}}, \Psi_{\mathrm{d}}\right\}$, which is considered to be satisfactory for the cases considered. Nevertheless, the design equations proposed for single-sided stiffeners should be further validated over a wider range of cases.

\section{Stiffener Design Procedure}

For designing a transverse stiffener for a plate subjected to coexistent shear and direct in-plane loading (Fig. 1), the following variables are considered:

- Components of the ultimate strength for simply supported panels: $\tau_{u}, \sigma_{c u}, \sigma_{b u}$;

- External stiffener forces for load bearing stiffeners: $Q_{1}$ (at one end), $Q_{2}$ (at both ends);

- Panel dimensions: $a, d, t$; 
- Initial imperfections: $w_{0 p}, w_{0 s}$, measured as in Fig. 3 of Ref. [10];

- $\quad$ Yield stresses of panel and stiffener material: $\sigma_{0 p}, \sigma_{0 s}$;

- $\quad$ Cross-sectional properties of the stiffener: $A_{s}, I_{s}, Z_{s}$ (see Section 3.3) and e (see Fig. 10);

The calculation of the ultimate strength of simply supported panels is not within the scope of the present study. Formulae for predicting the strength of individual panels subjected to shear and compressive loading have been given by Davidson [15]. For the panel shear strength $\tau_{\mathrm{u}}^{0}\left(\tau_{\mathrm{u}}\right.$ for pure shear), the predicted values are about $3 \sim 4 \%$ greater than the FE solutions [13]. Therefore, it is recommended that in the proposed stiffener design method, the shear strength of panels may be calculated using the formulae given by Davidson [15]. For panels subjected to combined loading, the components of the ultimate panel strength $\left(\tau_{\mathrm{u}}, \sigma_{\mathrm{cu}}, \sigma_{\mathrm{bu}}\right)$ may be evaluated by using the known ratio between the applied stresses and an available method in the design codes, such as the interaction equation in BS5400 [2].

\subsection{Intermediate Stiffeners}

The proposed design method for intermediate transverse stiffeners is summarized below.

(1) Calculate the critical buckling stresses for a simply supported panel, subjected to shear, compression and bending alone, using Eqs. (4), (5) and (6), respectively.

(2) Calculate the critical shear stress $\tau_{\text {cr }}$ in the presence of compression and bending using the known ratio between the applied stresses and the interaction equation (3).

(3) Calculate the equivalent shear stress $\tau_{\text {eq }}$ using Eq. (10), with the reduction factors $\beta_{\mathrm{c}}$ and $\beta_{\mathrm{b}}$ given by Eqs.(11) and (12).

(4) Calculate the elastic knife edge moment $\mathrm{M}_{\mathrm{km}}$ using Eq. (9), with $\tau_{\text {eq }}$ obtained in Step (3).

(5) Calculate the plastic factor $\mathrm{F}_{\mathrm{pl}}$ using Eq. (8), and the stiffener bending moment due to the panel bending effect $\mathrm{M}_{\mathrm{pb}}$ using Eq. (7).

(6) Calculate the design limit of the stiffener deflection, $\mathrm{w}_{\mathrm{sd}}$, using Eq. (34) for double-sided stiffeners, and Eq. (41) for single-sided stiffeners.

(7) Choose a trial stiffener section and calculate $A_{s}, I_{s}, Z_{s}$, and e (for single-sided stiffeners). The stiffener properties are defined in Eqs. (23) to (26). The trial stiffener size may be chosen in terms of experience. A suggested trial stiffener is the smallest stiffener which satisfies the following criteria: 


$$
\begin{gathered}
Z_{s} \geq \frac{M_{k m}+M_{o v}^{K E}}{0.8 \sigma_{0 s}} \\
I_{s} \geq\left(M_{k m}+M_{o v}^{K E}\right) \frac{d^{2}}{\pi^{2} E w_{s d}}
\end{gathered}
$$

with:

$$
\begin{aligned}
& M_{o v}^{K E}=\lim _{\Psi \rightarrow \infty} M_{o v} \\
& \quad=2 a\left(\frac{d^{2}}{4 a^{2}}+1\right) \cdot \tau t w_{0 s} / \sqrt{8.155\left(\frac{d^{2}}{4 a^{2}}+\frac{4 a^{2}}{d^{2}}\right)+13.99}
\end{aligned}
$$

In Eq. (42), the stiffener axial force $\mathrm{P}_{\mathrm{s}}$ is not included, but allowance for $\mathrm{P}_{\mathrm{s}}$ is made for the trial by reducing the stiffener yield stress $\sigma_{0 \mathrm{~s}}$ by $20 \%$.

(8) Calculate the axial force $P_{s}$ in the stiffener using Eq. (1), with the applied shear stress $\tau$ and the buckling shear stress $\tau_{\text {cr }}$ obtained in Step (2).

(9) Calculate the stiffener bending moment due to the overall buckling effect $\mathrm{M}_{\mathrm{ov}}$, using Eq. (13), with the overall buckling stresses $\tau_{\mathrm{ov}}, \sigma_{\mathrm{c}, \mathrm{ov}}$ and $\sigma_{\mathrm{b}, \mathrm{ov}}$ given by Eqs. (14), (15) and (16), respectively.

(10) Calculate the total stiffener moment $\mathrm{M}_{\mathrm{s}}=\mathrm{M}_{\mathrm{pb}}+\mathrm{M}_{\mathrm{ov}}$ (Eq. 22).

(11) Calculate the maximum stress in the stiffener $\sigma_{\mathrm{s}, \max }$. For double-sided stiffeners, Eq. (27) is used. For single-sided stiffeners, Eqs. (35) to (37) should be used for $\mathrm{d} / \mathrm{a} \leq 2$, and Eqs. (38) to (40) for $\mathrm{d} / \mathrm{a}>2$.

(12) Calculate the stiffener deflection at the ultimate load, $\mathrm{w}_{\mathrm{su}}$, using Eq. (31). For single-sided stiffeners, the moment $\mathrm{M}_{\mathrm{s}}$ in Eq. (31) should be replaced with the moment about the centroid axis 1-1 of the stiffener section, $\mathrm{M}_{\mathrm{s}, 1}$. as given by Eq. (35) for $\mathrm{d} / \mathrm{a} \leq 2$, and Eq. (38) for $\mathrm{d} / \mathrm{a}>2$.

(13) Check the strength and stiffness criteria, given in Eqs. (29) and (33), respectively.

(14) If either the strength criterion (Eq. 29) or the stiffness criterion (Eq. 33) is not satisfied, then the chosen stiffener size must be increased. Conversely, if both criteria are more than satisfied, then the chosen stiffener size may be reduced. Subsequent stiffener sizes may be checked by returning to step (8) in the design procedure.

The above procedure may be converted into a computer program, from which the optimum stiffener size can be obtained. An optimum stiffener is defined by the optimal model: 


$$
\begin{array}{ll}
\min A_{s} & \\
\text { subjected to: } & \sigma_{s, \max } \leq \sigma_{0 s} \\
& w_{s u} \leq w_{s d} \\
& A_{s}>0
\end{array}
$$

\subsection{Special Considerations for Load Bearing Stiffeners}

As required in BS5400, the section of a load bearing stiffener should be chosen to be double-sided and symmetric about the mid-plane of the plate.

For a stiffener loaded with external forces, either at one end or both ends, the total stiffener axial force $\mathrm{P}_{\mathrm{s}, \text { total }}$ is given by Eq. (28), and the stiffener bending moment due to the overall buckling effect $\mathrm{M}_{\mathrm{ov}}$ should be calculated using Eq. (17) or Eq. (19), which takes into account the destabilising effect caused by the external forces.

The applied external force is resisted by the stiffener itself and by part of the plate together. Nevertheless, since the panel is not designed to resist the external force applied at the end of the stiffener, it is consistent to assume that the external force is all taken by the stiffener itself. Therefore, it is suggested that when designing a load bearing stiffener, only the stiffener section should be considered.

\section{Comparisons of the Proposed Model with Existing Methods}

In this section, comparisons of the required stiffener sizes are made between the proposed model and several existing design methods, including three design codes (namely, BS5400 [2], Eurocode 3 [3] and AASHTO [4] and the methods proposed by Horne \& Grayson [14], by Rahal \& Harding [8], and by Stanway, Chapman \& Dowling [9]. Comparisons are made mainly for plates with a double-sided stiffener, subjected to pure shear, but single-sided flat bar stiffeners are also considered. For all the results described in this section, a flat bar stiffener with a side ratio of $h_{s} / t_{s}=10$ (for both double-sided and singlesided, as shown in Fig. 1) is assumed. 


\subsection{Double-Sided Stiffeners}

Table 4 lists the minimum values of the stiffener flexural rigidity, denoted as $\Psi_{\mathrm{d}}$, required according to the proposed model and the existing design methods for stiffened plates with a double-sided flat bar stiffener. Plates having a panel aspect ratio $\mathrm{d} / \mathrm{a}=0.5,1,2,3,5 \& 7$, and a slenderness ratio $\mathrm{b} / \mathrm{t}=80,120$ \&180, respectively, were considered.

To demonstrate the adequacy of the stiffeners given by the various design methods considered, the $\Psi_{\mathrm{d}}$ values were compared with the FE $\tau_{\mathrm{u}}{ }^{\prime}$ vs. $\Psi$ curves for all the cases considered ([5]). As an illustration, Fig. 13 shows the comparisons made for the cases of $d / a=0.5$ to 3 with $b / t=180$. It has been pointed out that the basic requirement for an adequate stiffener is to ensure that the ultimate strength for the stiffened plate is at least as great as the strength for the associated simply supported panel, represented by:

$$
\Psi_{d} \geq \Psi_{s s u}
$$

Also, an adequate stiffener should ensure that the plate strength is within the plateau of the $\tau_{\mathrm{u}}{ }^{\prime}$ vs. $\Psi$ curve.

\subsection{Single-Sided Stiffeners}

In Table 5, the minimum values of the stiffener flexural rigidity, $\Psi_{\mathrm{d}}$, required according to the various design methods are listed for stiffened plates of $\mathrm{d} / \mathrm{a}=2,5$ and $\mathrm{b} / \mathrm{t}=180$ with a single-sided flat bar stiffener having $h_{s} / t_{s}=10$, subjected to pure shear. In Fig. 14, the values of $\Psi_{d}$ for different design methods are compared with the finite element results of $\tau_{\mathrm{u}}{ }^{\prime}$ vs. $\Psi$. Also shown in Fig. 14 are the values of $\Psi_{\text {ssu }}$.

\subsection{Comments}

The results presented above demonstrate that there is a wide difference in the stiffeners required by the various existing design methods for a given plate geometry. This in itself was one of the strong reasons for carrying out the present investigation. 
From the validation against the FE results, it was found that the proposed design model gives consistently satisfactory stiffeners for all the cases examined ([5]), without being overly conservative. Of all the design methods considered, the proposed model is the only approach which gives adequate results for both double-sided and single-sided stiffeners. In comparison with BS5400 and Eurocode, the proposed model gives in general heavier stiffeners for $d / a \leq 2$ plates, and considerably lighter stiffeners for $d / a \geq 5$ plates.

For the double-sided stiffeners, it was found that the three design codes examined could give inadequate stiffeners in some cases. AASHTO gives satisfactory stiffeners for $b / t=80$, where the post-buckling behaviour of the plate is not important. For slender plates (e.g. b/t $\geq 180$ ), AASHTO severely underestimates the required stiffeners. BS5400 gives inadequate stiffeners for $d / a \leq 2$, but unduly conservative stiffeners for very tall plates (e.g. $d / a \geq 5$ ). Eurocode underestimates the stiffeners required for $d / a \leq 1$ and $b / t=180$. For $d / a \geq 5$ plates, the stiffener from Eurocode is unduly conservative. For tall plates with $\mathrm{b} / \mathrm{t}=180$, Eurocode gives stiffeners which are considerably greater than those from BS5400, due to the difference in the magnitude of the axial force caused by tension field action.

For the single-sided stiffener cases examined, the proposed model gives satisfactory results. However, it is recognised that more cases should be studied in the future.

\section{Conclusions}

Based on the non-linear buckling theory and FE solutions, a rational and usable design model for transverse stiffeners is proposed. The proposed design model requires that the transverse stiffener be designed to resist the coexistent bending moment and axial force in the stiffener. The bending moment is determined by adding the components of stiffener moment due to the local panel bending effect and the tendency for the stiffened plate to buckle overall. The axial force caused by the tension field action acts in the mid-plane of the plate, resulting in an additional bending moment for eccentric stiffeners due to the eccentricity of this axial force. For eccentric stiffeners the axial force may contribute up to about $70 \%$ of the total stress. This occurs when the plate bending effect acts in opposition to the eccentricity moment. The proposed method gives forces acting in the stiffener itself, which does not require the effective width 
of the plate to be considered. The moment of inertia is calculated about the centroidal axis of the actual stiffener section for both concentric and eccentric stiffeners.

Both strength and stiffness criteria were developed to quantify the required stiffener. The strength criterion requires that the maximum stress in the stiffener must not exceed the yield stress of the stiffener. The stiffness criterion requires that the stiffener deflection is sufficiently small to ensure that the stiffened plate is effectively divided.

The proposed design model has been validated against experimental results and FE solutions for stiffened plates and girders ([5]). It is found that the proposed design model gives satisfactory stiffeners for concentric and eccentric stiffeners, and for pure shear, shear and compression, and shear and bending, respectively. When compared with existing design methods, it is found that the proposed model gives more consistent stiffener sizes in relation to those required to satisfy the design criteria. The extent of the variability of existing methods can be seen in Tables 41 and 5, and Figures 13 and 14.

Acknowledgment: The work reported here was sponsored by the Engineering and Physical Sciences Research Council (EPSRC).

\section{REFERENCES}

[1] Skaloud, M., Optimum rigidity of stiffeners of webs and flanges, Plated Structures: Stability and Strength, Narayanan, R. ed., Applied Science Publishers, London, 1983, 103-134.

[2] BS5400. Steel, Concrete and Composite Bridges, Part 3: Code of Practice for Design of Steel Bridges, British Standard Institution (BSI), London, 1982.

[3] Eurocode 3. Design of Steel Structures, Part 1-1: General - General Rules and rules for buildings. European Committee for Standardization, Brussels, 1994.

[4] AASHTO. Standard Specifications for Highway Bridges. 16th Ed. American Association of State Highway and Transportation Officials, Washington, D.C., 1996.

[5] Xie, M. Behaviour and Design of Transversely Stiffened Plates Subject to Combined Shear and Direct In-plane Loading. Ph.D Thesis, Dept. of Civil and Environmental Engineering, Imperial 
College, London, 2000.

[6] Stanway, G. The Behaviour and Design of Transversely Stiffened Plates Subject to In-plane Shear Forces. Ph.D Thesis, Dept. of Civil and Environmental Engineering, Imperial College, London, 1990.

[7] Rahal, K. N. and Harding, J. E. Transversely stiffened girder webs subjected to shear loading - part 1: behaviour. Proc. Instn Civ. Engrs, Part 2, 89(3), 1990, 47-65.

[8] Rahal, K. N. and Harding, J. E. Transversely stiffened girder webs subjected to shear loading - part 2: stiffener design. Proc. Instn Civ. Engrs, Part 2, 89(3), 1990, 67-87.

[9] Stanway, G. S., Chapman, J. C. and Dowling, P. J. A design model for intermediate web stiffeners. Proc. Instn Civ. Engrs Structs \& Bldgs, 116(2), 1996, 54-68.

[10] Xie, M. and Chapman, J. C. Design of web stiffeners: axial forces. Journal of Constructional Steel Research, 59(8), 2003, 1035-1056.

[11] Xie, M. and Chapman, J. C. Design of web stiffeners: local panel bending effects. Journal of Constructional Steel Research, 60(10), 2004, 1425-1452

[12] Rockey, K. C., Valtinat, G. and Tang, K. H. The design of transverse stiffeners on webs loaded in shear --an ultimate approach. Proc. Instn Civ. Engrs, Part 2, 71, 1981, 1069-1099.

[13] Fortune, L. H. Design of Intermediate Stiffeners for Girder Webs Subject to Shear. Ph.D Thesis, Dept. of Civil and Environmental Engineering, Imperial College, London, 2000.

[14] Horne, M. R. and Grayson, W. R. Parametric finite element study of transverse stiffeners for webs in shear, Instability and Plastic Collapse of Steel Structures, Morris, L. J. ed., Granada Publishing, London, 1983.

[15] Davidson, P. C. Design of Plate Panels under Biaxial Compression, Shear and Lateral Pressure. Ph.D Thesis, Dept. of Civil and Environmental Engineering, Imperial College, London, 1989.

\section{NOTATION}

a

$\mathrm{A}_{\mathrm{s}} \quad$ cross-sectional area of stiffener

b smaller panel dimension, $b=\min \{a, d\}$

d panel depth and length of stiffener

$\mathrm{D}$

panel width

flexural rigidity of plate, $\mathrm{D}=\mathrm{Et}^{3} / 12\left(1-v^{2}\right)$ 

section of a single-sided stiffener modulus of elasticity $\left(\mathrm{E}=2.05 \times 10^{5} \mathrm{~N} / \mathrm{mm}^{2}\right)$

$\mathrm{F}_{\mathrm{pl}}$ $\mathrm{h}$

$\mathrm{h}_{\mathrm{s}}$

$\mathrm{I}_{\mathrm{s}}$

$\mathrm{k}_{\mathrm{cr}}$

$\mathrm{M}_{\mathrm{k}}$

$\mathrm{M}_{\mathrm{km}}$

$\mathrm{M}_{\mathrm{pb}}$

$\mathrm{M}_{\mathrm{ov}}$

$\mathrm{M}_{\mathrm{s}}$

$\mathrm{P}_{\mathrm{s}}$

$\mathrm{Q}_{1}$

$\mathrm{Q}_{1, \mathrm{ov}}$

$\mathrm{Q}_{2}$

$\mathrm{Q}_{2, \mathrm{ov}}$

$\mathrm{t}$

$t_{\mathrm{s}}$

$\mathrm{w}_{\mathrm{p}}$

$\mathrm{w}_{0 \mathrm{p}}$

$\mathrm{w}_{0 \mathrm{~s}}$

$\mathrm{W}_{\mathrm{sd}}$

$\mathrm{w}_{\mathrm{su}}$

$\alpha$

$\beta_{\mathrm{b}}$

$\beta_{\mathrm{c}}$

V

$\sigma_{\mathrm{b}}$ empirical factor for the effect of panel plasticity on the knife edge moment

$\mathrm{h}_{\mathrm{s}}+\mathrm{t} / 2$ (Fig. 1)

depth of stiffener on one side of plate (Fig. 1)

moment of inertia of stiffener alone

critical buckling stress coefficient

bending moment in straight knife edge, derived from the lateral distributed force $\mathrm{q}_{\mathrm{k}}$

maximum magnitude of bending moment $\mathrm{M}_{\mathrm{k}}$ along the straight knife edge

stiffener bending moment due to the effect of local panel bending, $\mathrm{M}_{\mathrm{pb}}=\mathrm{F}_{\mathrm{pl}} \cdot \mathrm{M}_{\mathrm{km}}$

stiffener bending moment due to the overall buckling effect

stiffener bending moment

axial force in stiffener, $\mathrm{P}_{\mathrm{s}}>0$ for compression

external force acting at one end of the stiffener

overall buckling load for plate subjected to external force acting at one end of the stiffener

external force acting at both ends of the stiffener

overall buckling load for plate subjected to external force acting at both ends of the stiffener

thickness of plate panel

thickness of stiffener

additional panel deflection

magnitude of initial panel deflection

magnitude of initial stiffener deflection

the design limit of the additional stiffener deflection

additional stiffener deflection at the ultimate load of stiffened plates

panel side ratio defined by $\alpha=\max (\mathrm{d} / \mathrm{a}, \mathrm{a} / \mathrm{d}) \geq 1$

equivalent shear stress factor for bending

equivalent shear stress factor for compression

Poisson's ratio $(v=0.3)$

applied bending stress (Fig.1) 


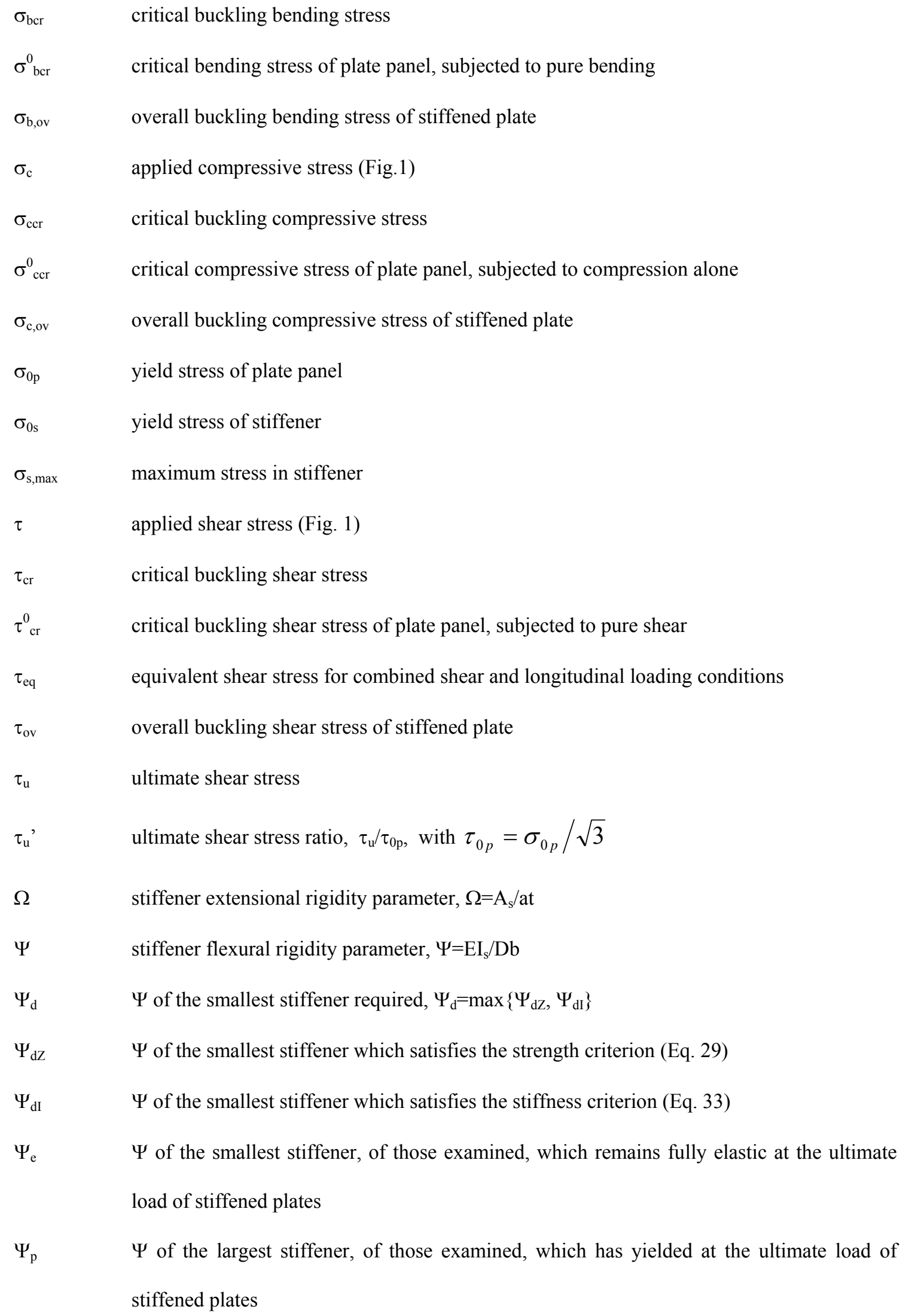

$\Psi_{\mathrm{p}} \quad \Psi$ of the largest stiffener, of those examined, which has yielded at the ultimate load of stiffened plates

$\Psi_{\text {ssu }} \quad$ the stiffener rigidity required to develop the ultimate strength of simply supported panels 
Table 1 Overall Buckling Model for Individual Loading Conditions

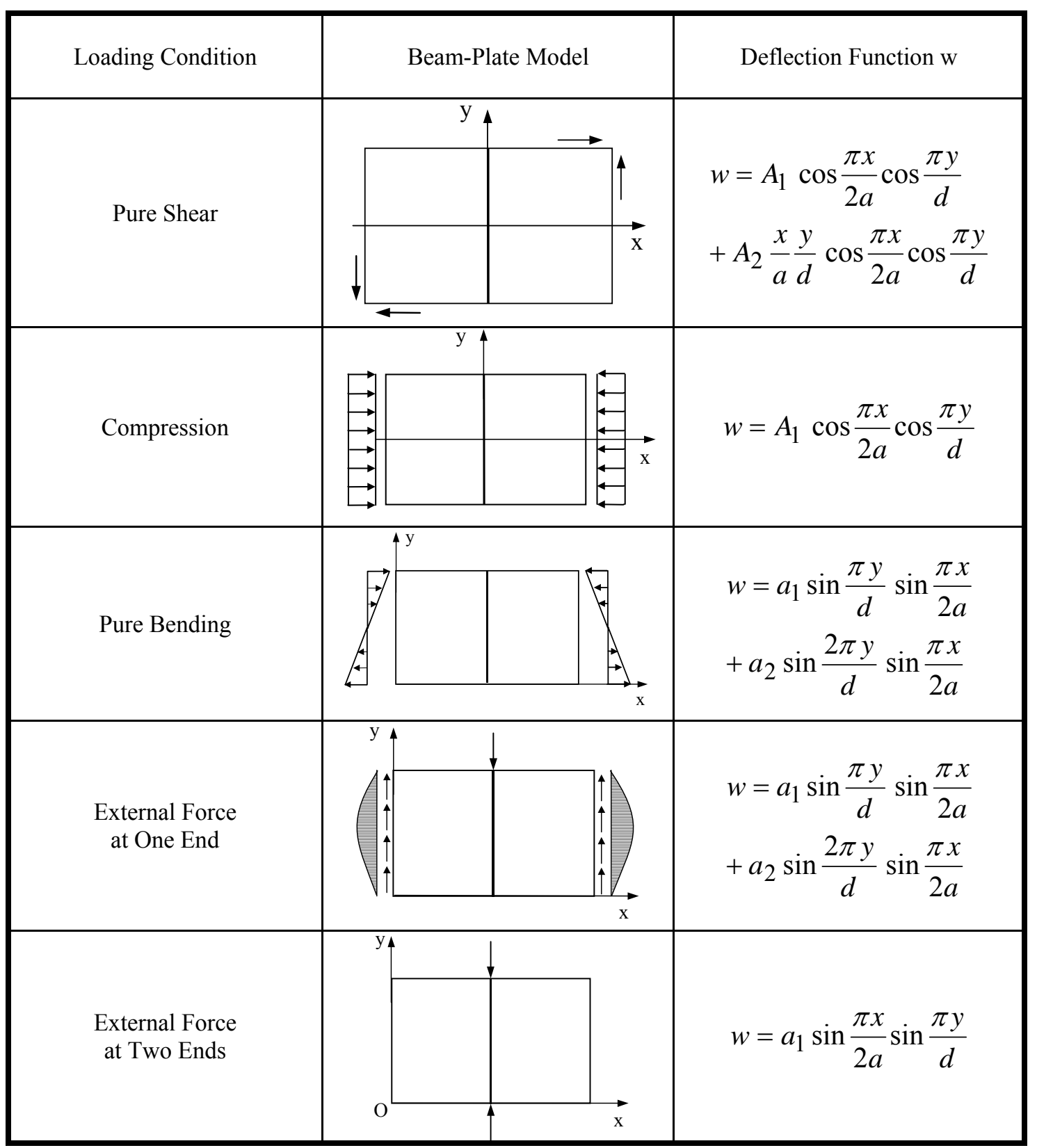


Table 2 Comparison of the required stiffener rigidities $\Psi_{\mathrm{dZ}}$ and $\Psi_{\mathrm{dI}}$ for combined loading conditions. $\mathrm{d} / \mathrm{a}=2, \sigma_{0 \mathrm{p}}=\sigma_{0 \mathrm{~s}}=355 \mathrm{~N} / \mathrm{mm}^{2}$

\begin{tabular}{|c|c|c|c|c|}
\hline$\sigma_{\mathrm{c}}: \tau$ or $\sigma_{\mathrm{b}}: \tau$ & $\Psi_{\mathrm{dZ}}$ & $\Psi_{\mathrm{d} I}$ & $\Psi_{\mathrm{d}}$ & $\Psi_{\mathrm{d}} / \Psi_{\mathrm{d}, \text { shear }}$ \\
\hline \multicolumn{5}{|c|}{ (a) Combined shear and compression conditions, a/t=80 } \\
\hline $1: 0$ & 23.9 & 81.2 & 81.2 & 0.306 \\
\hline $1: 2$ & 88.9 & 157.9 & 157.9 & 0.594 \\
\hline $1: 5$ & 42.4 & 138.8 & 138.8 & 0.522 \\
\hline $0: 1$ & 98.3 & 265.7 & 265.7 & 1.0 \\
\hline \multicolumn{5}{|c|}{ (b) Combined shear and bending conditions, a/t=180 } \\
\hline $1: 0$ & 19.15 & 143.6 & 143.6 & 0.135 \\
\hline $2: 1$ & 97.93 & 328.9 & 328.9 & 0.309 \\
\hline $1: 1$ & 146.95 & 505.8 & 505.8 & 0.476 \\
\hline $0: 1$ & 375.1 & 1063.5 & 1063.5 & 1.0 \\
\hline
\end{tabular}

Table 3 Required stiffener rigidities $\Psi_{\mathrm{dZ}}$ and $\Psi_{\mathrm{dI}}$ for single-sided stiffeners.

Pure shear. b/t=180, $\sigma_{0 \mathrm{p}}=\sigma_{0 \mathrm{~s}}=355 \mathrm{~N} / \mathrm{mm}^{2} . \Psi=\mathrm{EI}_{\mathrm{s}} / \mathrm{Db}, \mathrm{I}_{\mathrm{s}}$ as in Eq. (26)

\begin{tabular}{|c|c|c|}
\hline $\mathrm{d} / \mathrm{a}$ & $\Psi_{\mathrm{dZ}}$ & $\Psi_{\mathrm{dI}}$ \\
\hline 2 & 131.4 & 213.7 \\
\hline 5 & 897.6 & 3488 \\
\hline
\end{tabular}


Table 4 Required stiffener flexural rigidities $\Psi_{\mathrm{d}}$. Double-sided flat bar stiffeners $\left(\mathrm{h}_{\mathrm{s}} / \mathrm{t}_{\mathrm{s}}=10\right)$ Pure shear. $\sigma_{0 \mathrm{p}}=\sigma_{0 \mathrm{~s}}=245 \mathrm{~N} / \mathrm{mm}^{2} . \Psi=\mathrm{EI}_{\mathrm{s}} / \mathrm{Db}, \mathrm{I}_{\mathrm{s}}$ as in Eq. (24)

\begin{tabular}{|c|c|c|c|c|c|c|c|c|}
\hline b/t & $\mathrm{d} / \mathrm{a}$ & $\begin{array}{c}\text { Proposed } \\
\text { Model } \\
\text { (Note 1) }\end{array}$ & $\begin{array}{l}\text { BS5400 } \\
\text { (Note 2) }\end{array}$ & $\begin{array}{c}\text { Eurocode } \\
\text { (Note 2) }\end{array}$ & $\begin{array}{l}\text { AASHTO } \\
\text { (Note 2) }\end{array}$ & $\begin{array}{l}\text { Horne \& } \\
\text { Grayson }\end{array}$ & $\begin{array}{l}\text { Rahal \& } \\
\text { Harding } \\
\text { (Note 1) }\end{array}$ & $\begin{array}{c}\text { Stanmay } \\
\text { et al } \\
\text { (Note 1) }\end{array}$ \\
\hline \multirow{6}{*}{80} & 0.5 & 11.27 & 0.888 & 8.183 & 10.92 & 9.876 & 12.57 & 13.07 \\
\hline & 1 & 6.037 & 2.422 & 16.33 & 5.460 & 9.876 & 7.793 & 11.17 \\
\hline & 2 & 131.9 & 45.39 & 130.8 & 87.36 & 66.34 & 57.85 & 150.9 \\
\hline & 3 & 240.7 & 233.2 & 442.5 & 223.9 & 119.5 & 194.4 & 431.0 \\
\hline & 5 & 580.4 & 1838 & 2055 & 660.7 & 225.8 & 999.5 & 700.2 \\
\hline & 7 & 1105 & 7000 & 5617 & 1316 & 332.2 & 2619 & 1774 \\
\hline \multirow{6}{*}{120} & 0.5 & 24.04 & 5.757 & 8.187 & 10.92 & 29.81 & 13.94 & 27.62 \\
\hline & 1 & 16.10 & 8.180 & 16.38 & 5.460 & 29.81 & 13.51 & 29.61 \\
\hline & 2 & 294.7 & 96.84 & 130.9 & 87.36 & 119.5 & 71.06 & 309.4 \\
\hline & 3 & 444.3 & 388.1 & 442.1 & 223.9 & 199.3 & 232.7 & 648.8 \\
\hline & 5 & 1024 & 2308 & 2447 & 660.7 & 358.8 & 1001 & 1019 \\
\hline & 7 & 2037 & 7911 & 6685 & 1316 & 518.3 & 2976 & 2622 \\
\hline \multirow{6}{*}{180} & 0.5 & 53.09 & 10.12 & 8.645 & 10.92 & 59.72 & 13.23 & 59.36 \\
\hline & 1 & 42.25 & 22.04 & 16.40 & 5.460 & 59.72 & 16.51 & 58.85 \\
\hline & 2 & 587.9 & 192.5 & 494.6 & 87.36 & 199.3 & 72.84 & 609.2 \\
\hline & 3 & 714.6 & 598.4 & 2149 & 230.0 & 318.9 & 221.0 & 1022 \\
\hline & 5 & 1588 & 2796 & 9946 & 869.9 & 558.1 & 841.0 & 1554 \\
\hline & 7 & 3090 & 8645 & 24677 & 1903 & 797.4 & 2088 & 3888 \\
\hline
\end{tabular}

Note 1: Applied shear taken as the panel strength $\tau_{\mathrm{u}}$ from FE analysis.

Note 2: Applied shear taken as the panel strength $\tau_{\mathrm{u}}$, calculated from the same code.

Table 5 Required stiffener flexural rigidities $\Psi_{\mathrm{d}}$. Single-sided flat bar stiffeners $\left(\mathrm{h}_{\mathrm{s}} / \mathrm{t}_{\mathrm{s}}=10\right)$

Pure shear. $\sigma_{0 \mathrm{p}}=\sigma_{0 \mathrm{~s}}=355 \mathrm{~N} / \mathrm{mm}^{2} . \Psi=\mathrm{EI}_{\mathrm{s}} / \mathrm{Db}, \mathrm{I}_{\mathrm{s}}$ as in Eq. (26)

\begin{tabular}{|c|c|c|c|c|c|c|c|}
\hline \multirow{2}{*}{$\mathbf{b} / \mathbf{t}$} & $\mathbf{d} / \mathbf{a}$ & $\begin{array}{c}\text { Propose } \\
\mathbf{d} \\
\text { Model } \\
\text { (Note 1) }\end{array}$ & BS5400 & $\begin{array}{c}\text { AASHI } \\
\text { (Note 2) }\end{array}$ & $\begin{array}{c}\text { Horne \& } \\
\text { Grayson }\end{array}$ & $\begin{array}{c}\text { Rahal \& } \\
\text { Harding } \\
\text { (Note 1) }\end{array}$ & $\begin{array}{c}\text { Stanway } \\
\text { et al } \\
\text { (Note 1) }\end{array}$ \\
\hline \multirow{2}{*}{180} & 2 & 213.7 & 346.2 & 407.3 & 62.0 & 25.78 & 217.5 \\
\cline { 2 - 8 } & 5 & 3488 & 3821 & 3429 & 170.0 & 813.4 & 453.2 \\
\hline
\end{tabular}

Note 1: Applied shear taken as the panel strength $\tau_{\mathrm{u}}$ from FE analysis [1].

Note 2: Applied shear taken as the panel strength $\tau_{\mathrm{u}}$, calculated from the same code. 


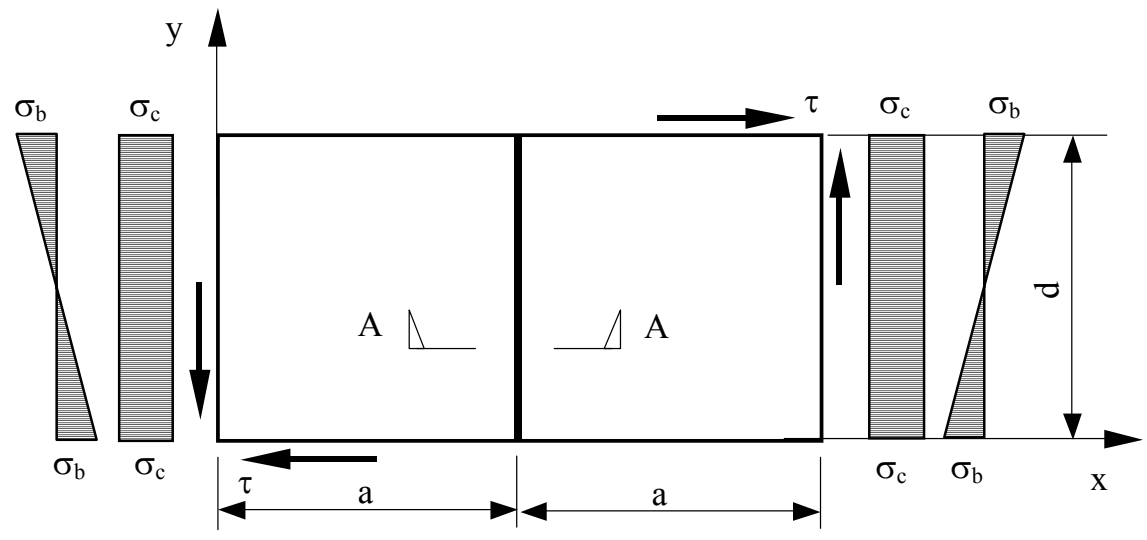

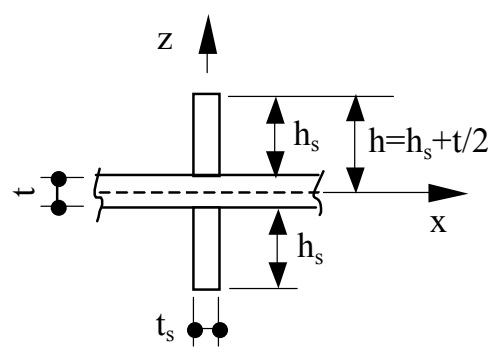

Double-sided stiffener

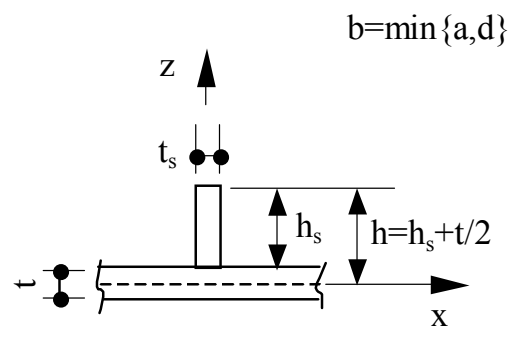

Single-sided stiffener

Section A-A

Fig. 1 Two-panel stiffened plate subjected to combined shear, compression and bending

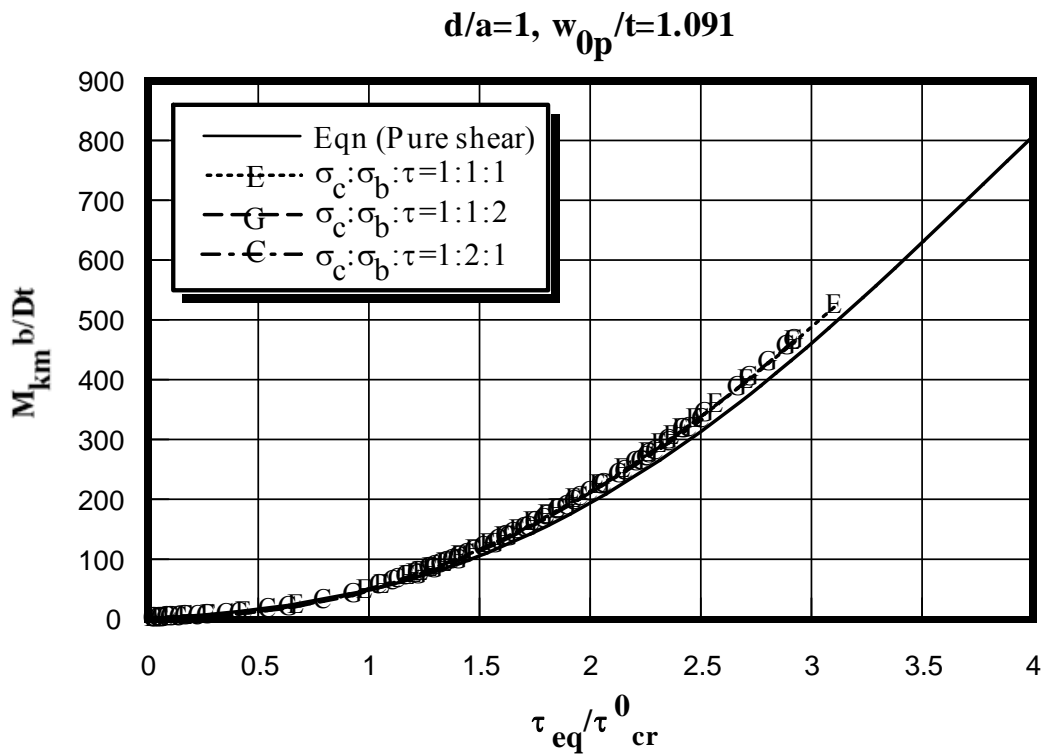

Fig. 2 Comparisons of the knife edge moments between the proposed equations and FE solutions. Coexistent shear, compression and bending. Plates with a straight knife edge. $\tau_{\mathrm{eq}}$ as in Eq. (10). 

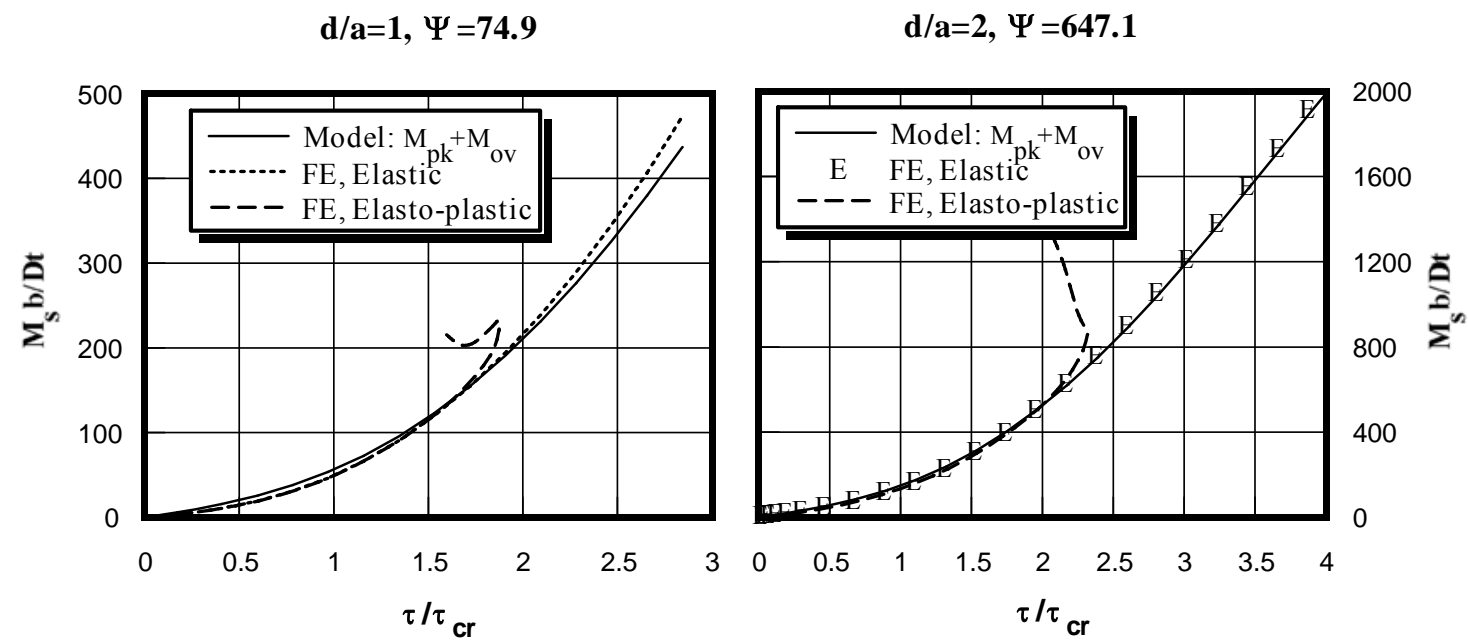

$\mathrm{d} / \mathrm{a}=5, \Psi=1580$

$$
\mathrm{d} / \mathrm{a}=7, \Psi=4993
$$
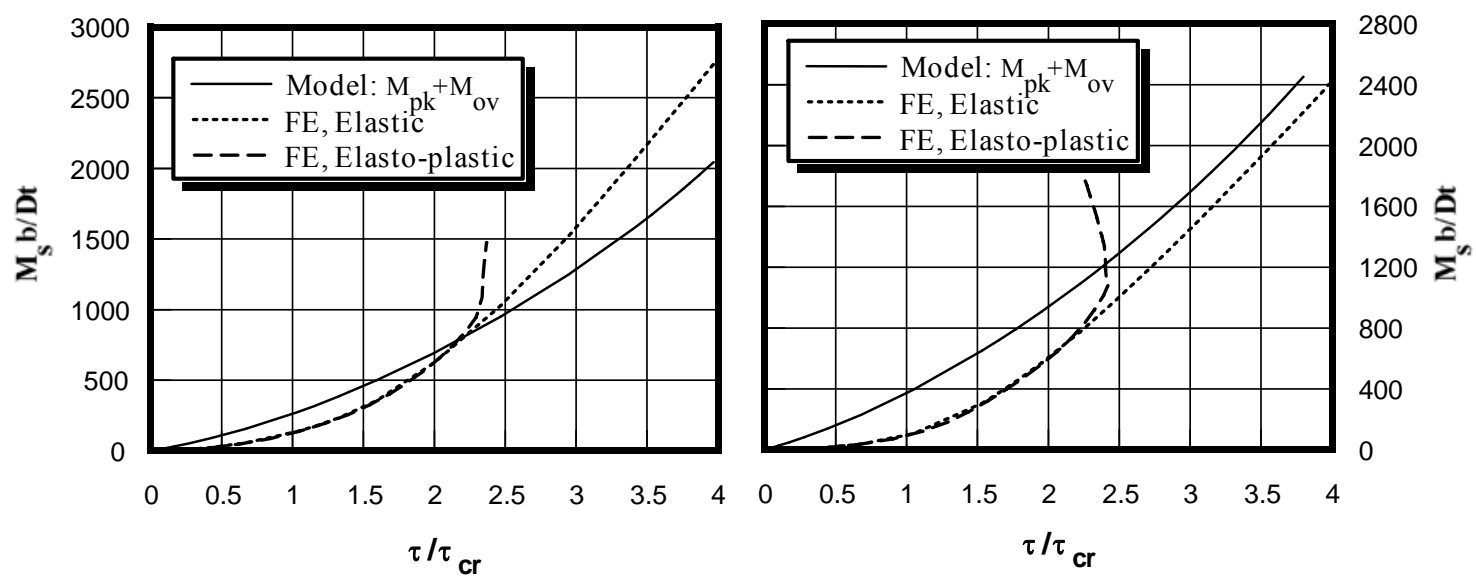

Fig. 3 Comparison of the elastic stiffener moment from the proposed model with the FE solutions.

Plates with an imperfect stiffener. $\mathrm{b} / \mathrm{t}=180 . \sigma_{0 \mathrm{p}}=\sigma_{0 \mathrm{~s}}=355 \mathrm{~N} / \mathrm{mm}^{2}$. Pure shear 


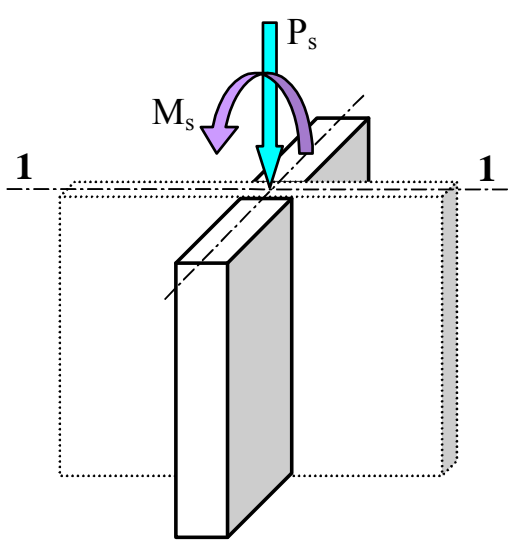

(a) Double-sided stiffener

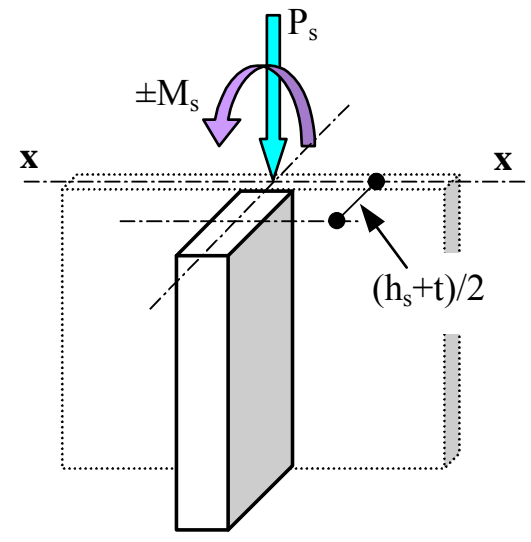

(b) Single-sided stiffener

Fig. 4 Design forces acting in the stiffener 


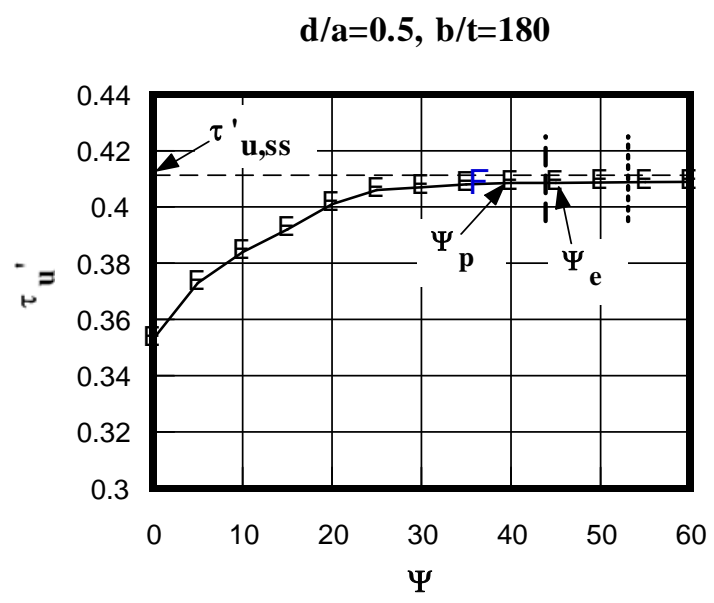

$\mathbf{d} / \mathbf{a}=\mathbf{1}, \mathbf{b} / \mathbf{t}=\mathbf{1 8 0}$

$d / a=2, b / t=180$
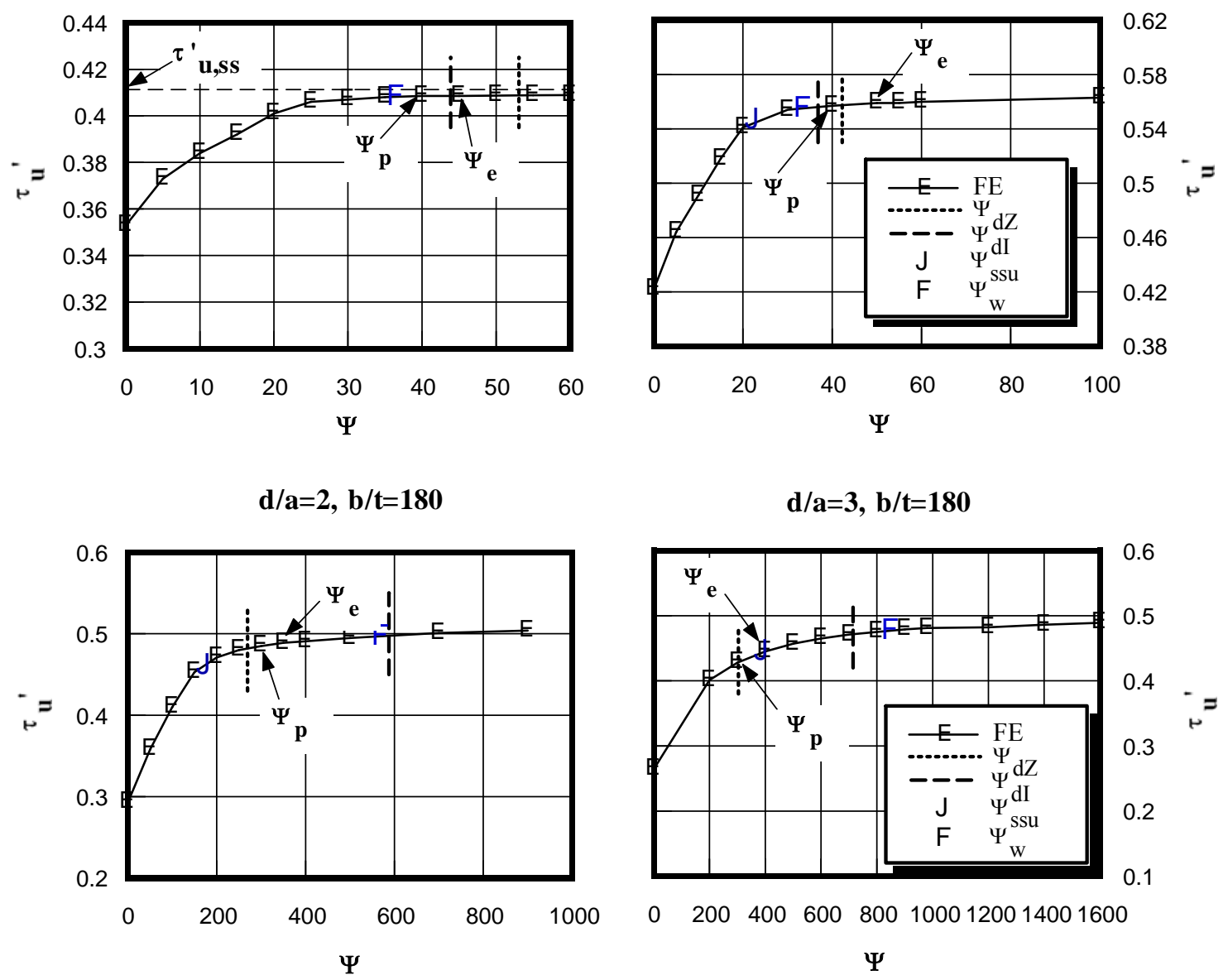

Fig. 5 Comparison of stiffener requirements from the proposed model, with the $\tau_{\mathrm{u}}{ }^{\prime}$ vs. $\Psi$ results from FE analyses, given by Fortune [13], with $\sigma_{0 \mathrm{p}}=\sigma_{0 \mathrm{~s}}=245 \mathrm{~N} / \mathrm{mm}^{2} . . \Psi=\mathrm{EI}_{\mathrm{s}} / \mathrm{Db}$. Pure shear 


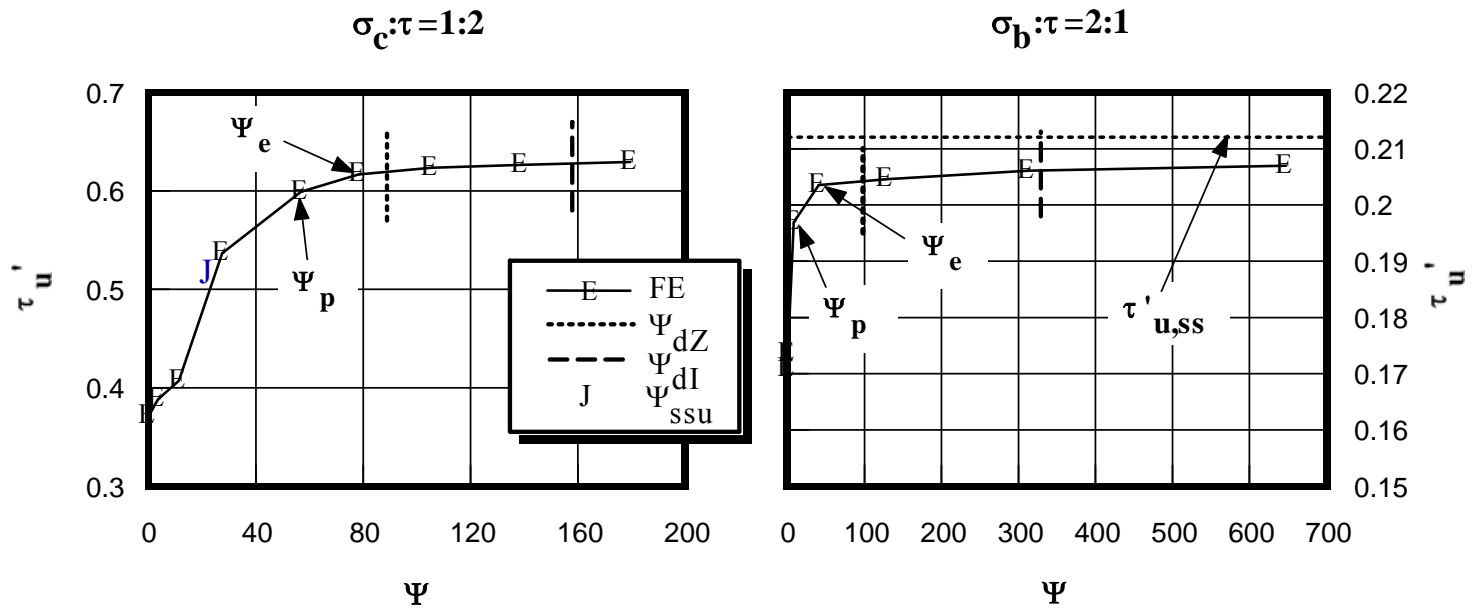

Fig. 6 Comparison of stiffener requirements from the proposed model, with the $\tau_{\mathrm{u}}$ ' vs. $\Psi$ results from FE analyses, with $\sigma_{0 \mathrm{p}}=\sigma_{0 \mathrm{~s}}=355 \mathrm{~N} / \mathrm{mm}^{2} . \mathrm{d} / \mathrm{a}=2, \mathrm{~b} / \mathrm{t}=180 . \Psi=\mathrm{EI}_{\mathrm{s}} / \mathrm{Db}$. Combined loading conditions.

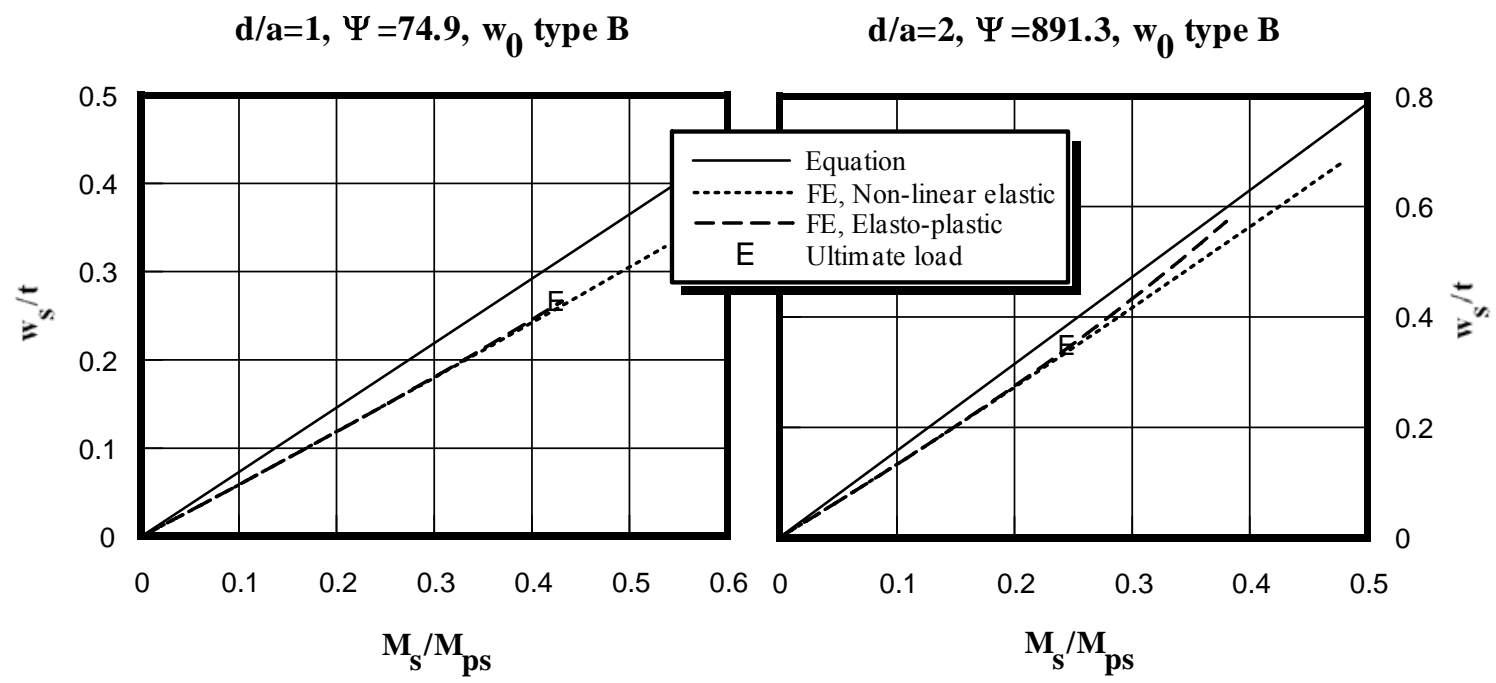

Fig. 7 Comparison of $\mathrm{w}_{\mathrm{s}}$ vs. $\mathrm{M}_{\mathrm{s}}$ curves from finite element analyses with Eq. (31). Pure shear. Initial imperfection $\mathrm{w}_{0}$ as in Fig. 3 of Ref. [10]. $\sigma_{0 \mathrm{p}}=\sigma_{0 \mathrm{~s}}=355 \mathrm{~N} / \mathrm{mm}^{2} . \Psi=\mathrm{EI} / \mathrm{Db}$ 

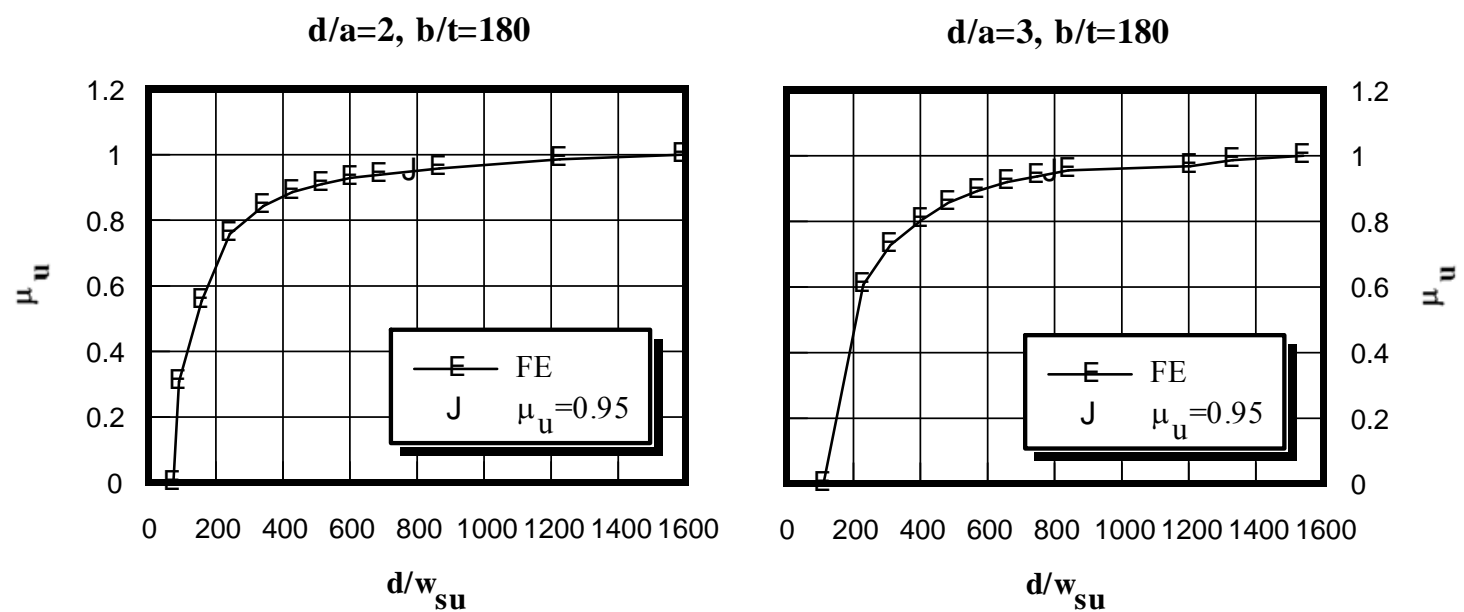

Fig. 8 Variation in the ultimate strength ratio $\mu_{\mathrm{u}}$ with the stiffener deflection at the ultimate load $\mathrm{w}_{\mathrm{su}}$. Produced from the FE solutions by Fortune [13], with $\sigma_{0 \mathrm{p}}=\sigma_{0 \mathrm{~s}}=245 \mathrm{~N} / \mathrm{mm}^{2}$. $\mu_{\mathrm{u}}$ as in Eq. (32). Pure shear

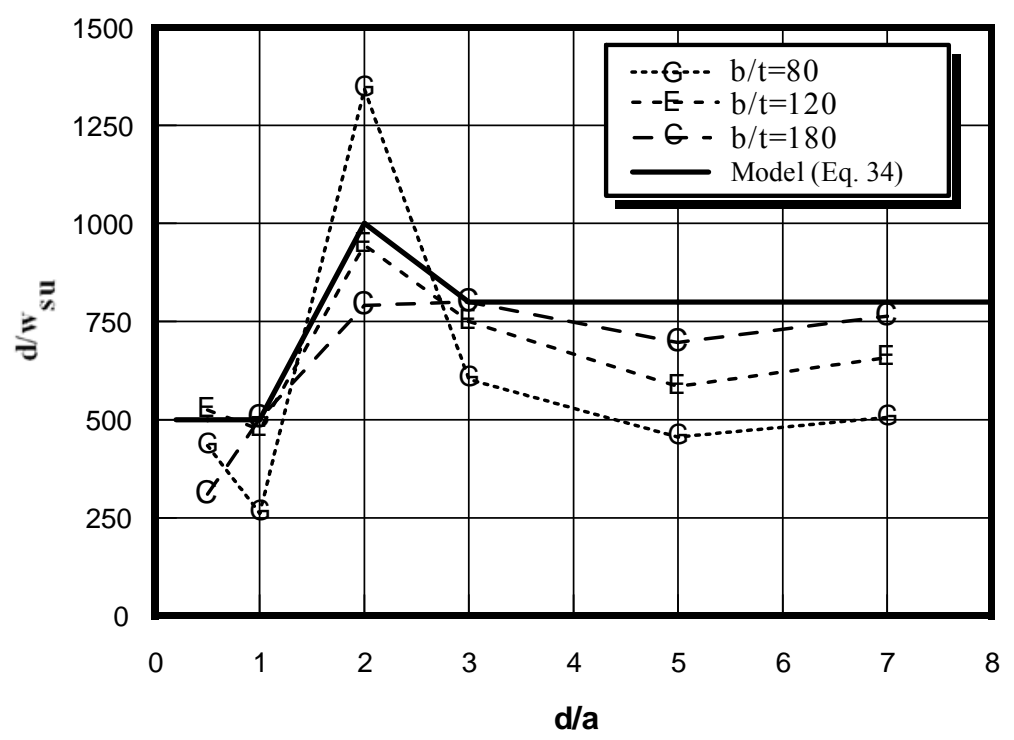

Fig. 9 Values of the stiffener deflection at the ultimate load $\mathrm{w}_{\mathrm{su}}$ for $\mu_{\mathrm{u}}=0.95$. Pure shear.

Proposed design limit of the stiffener deflection as given in Eq. (34). $\mu_{\mathrm{u}}$ as in Eq. (32) 


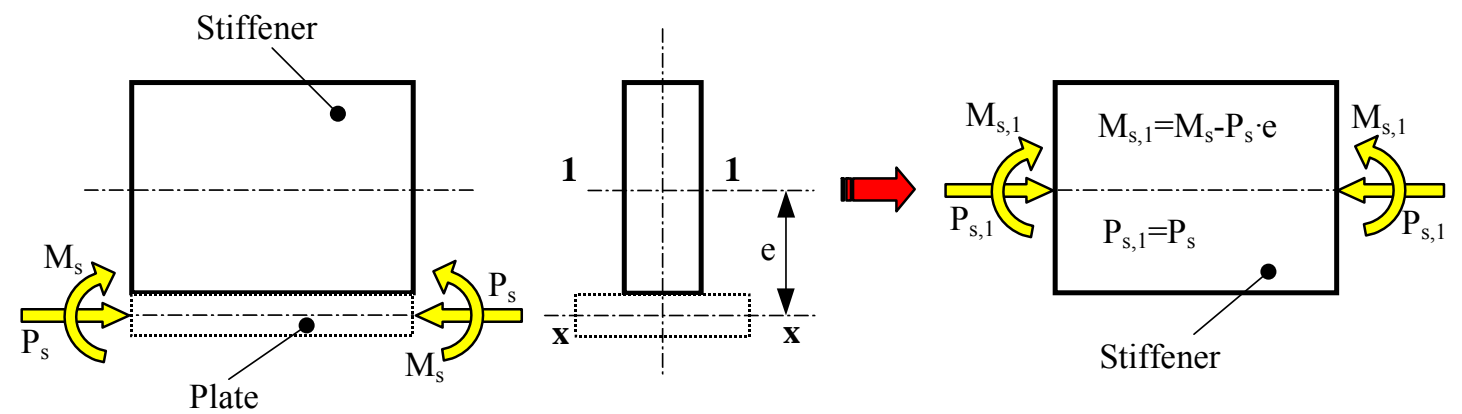

(a) Case 1 , for $\mathrm{d} / \mathrm{a} \leq 2$

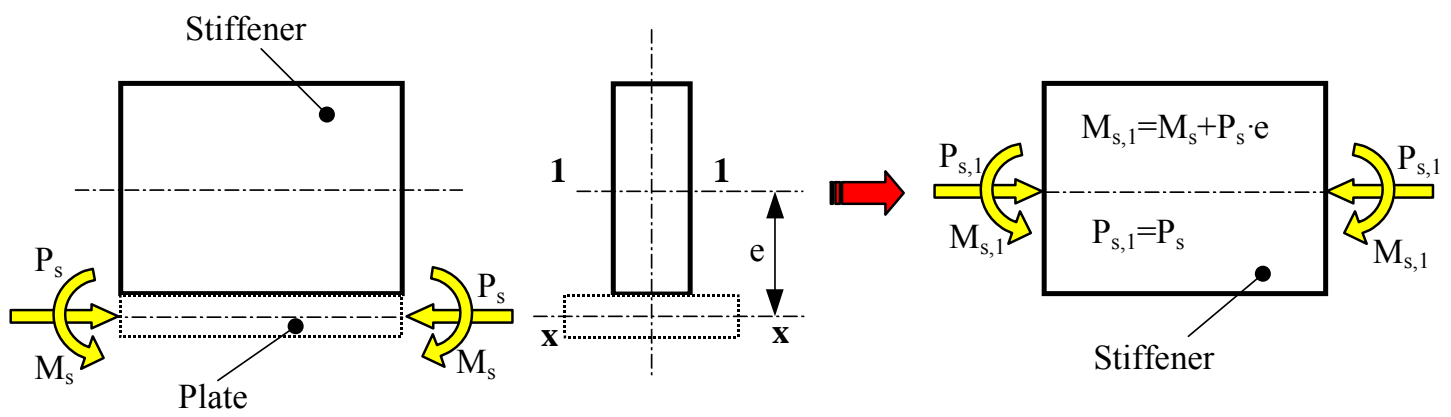

(b) Case 2, for $\mathrm{d} / \mathrm{a}>2$

Fig. 10 Possible combinations of the axial force and the bending moment in a single-sided stiffener.
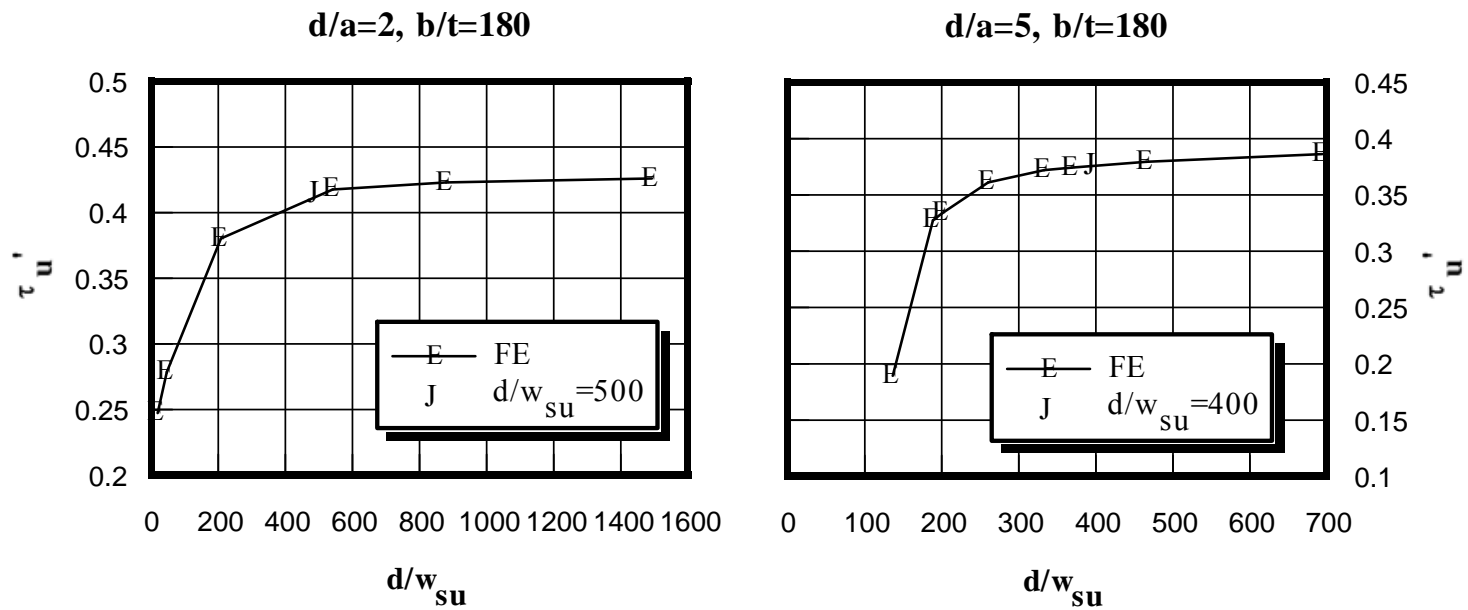

Fig. 11 Relationship of the ultimate shear strength and the stiffener deflection at the ultimate load. Plates with a single-sided stiffener. $\mathrm{w}_{0}$ : type $\mathrm{B}$ for $\mathrm{d} / \mathrm{a}=2$; type $\mathrm{A}$ for $\mathrm{d} / \mathrm{a}=5$, as in Fig. 3 of Ref. [10] 


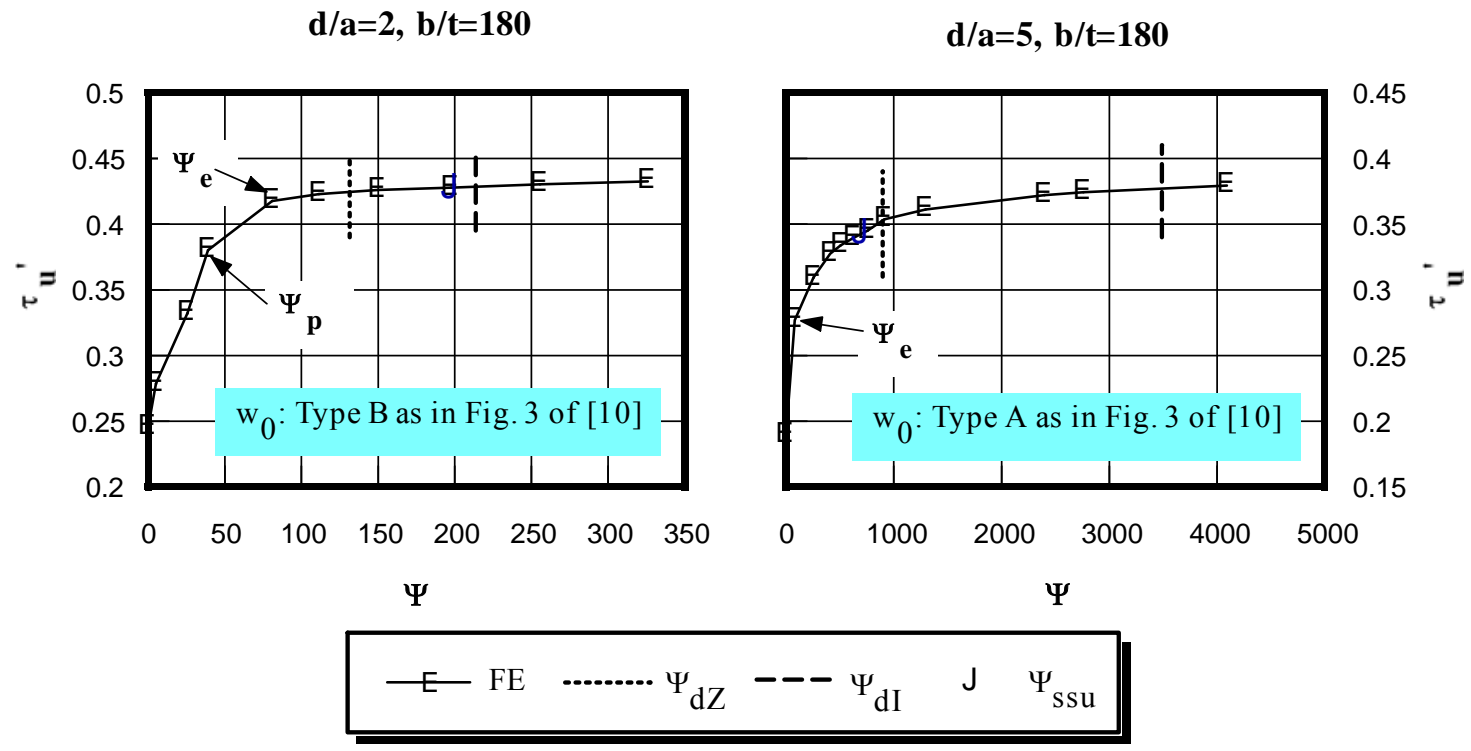

Fig. 12 Comparison of stiffener requirements from the proposed model, with the $\tau_{u}{ }^{\prime} v s$. FE analyses. $\sigma_{0 \mathrm{p}}=\sigma_{0 \mathrm{~s}}=355 \mathrm{~N} / \mathrm{mm}^{2}$. Single-sided stiffeners, $\Psi=E I_{\mathrm{s}} / \mathrm{Db}, \mathrm{I}_{\mathrm{s}}$ as in Eq. (26). Pure shear 
$\mathrm{d} / \mathbf{a}=\mathbf{0 . 5}, \mathbf{b} / \mathbf{t}=180$

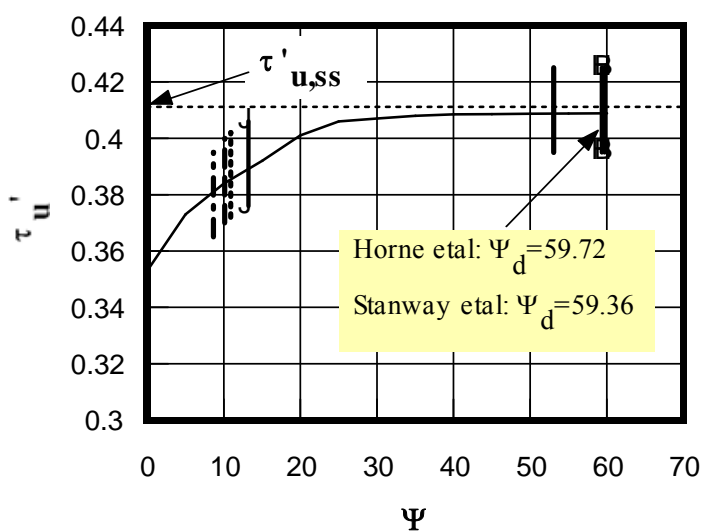

$d / a=2, b / t=180$

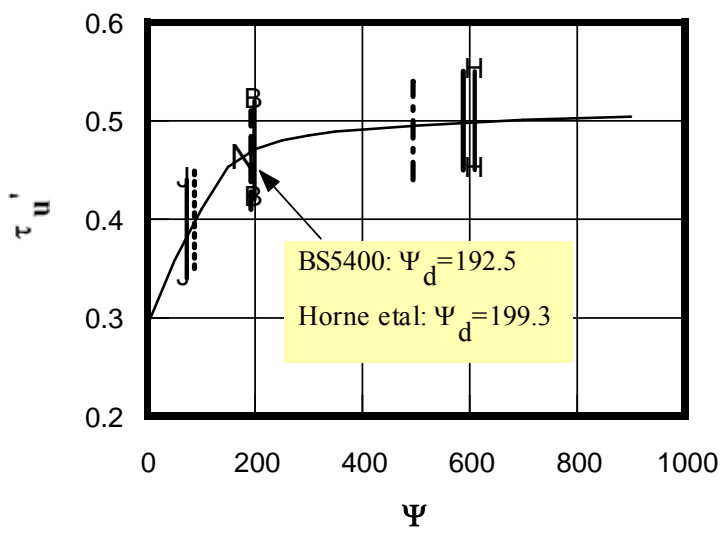

$\mathbf{d} / \mathbf{a}=\mathbf{1}, \mathbf{b} / \mathbf{t}=\mathbf{1 8 0}$

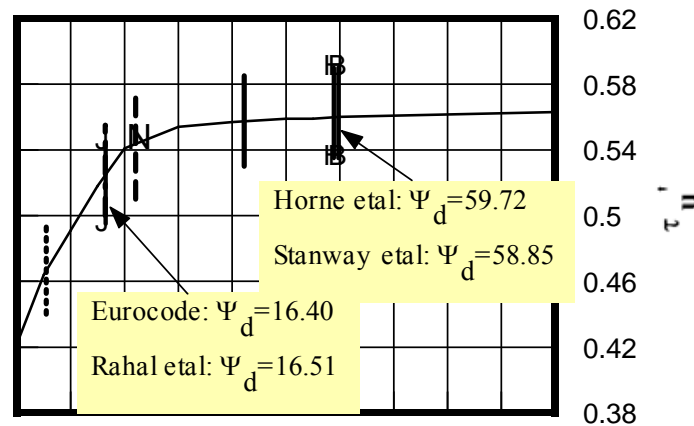

$\begin{array}{lllllllllll}0 & 10 & 20 & 30 & 40 & 50 & 60 & 70 & 80 & 90 & 100\end{array}$

$\Psi$

$d / a=3, b / t=180$

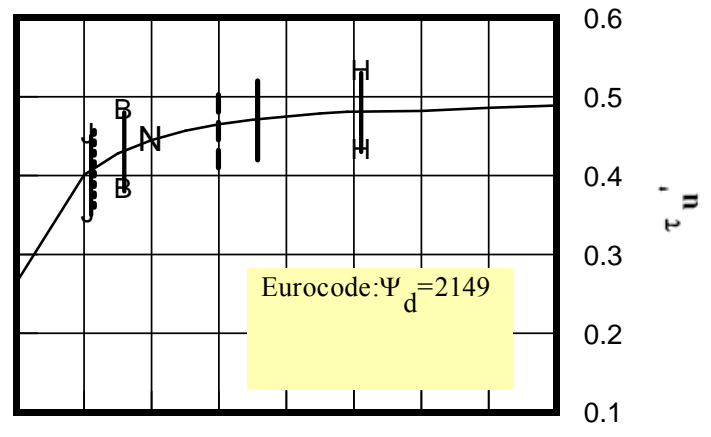

02004006008001000120014001600

$\Psi$

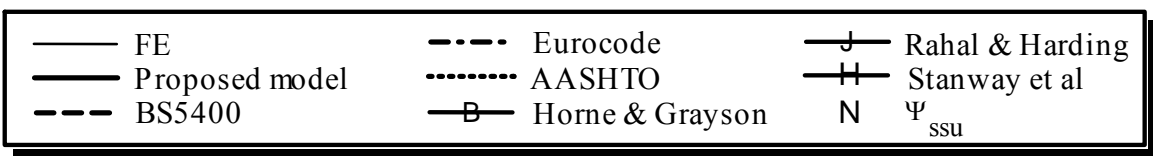

Fig. 13 Comparison of the stiffener flexural rigidity $\Psi_{\mathrm{d}}$ required by the proposed model and the existing methods, with the FE $\tau_{\mathrm{u}}{ }^{\prime}$ vs. $\Psi$ results from [13]. Double-sided flat bar stiffeners $\left(\mathrm{h}_{\mathrm{s}} / \mathrm{t}_{\mathrm{s}}=10\right)$ $\sigma_{0 \mathrm{p}}=\sigma_{0 \mathrm{~s}}=245 \mathrm{~N} / \mathrm{mm}^{2} . \Psi=\mathrm{EI}_{\mathrm{s}} / \mathrm{Db}, \mathrm{I}_{\mathrm{s}}$ as in Eqn. (24). Pure shear 
$d / a=2, b / t=180$

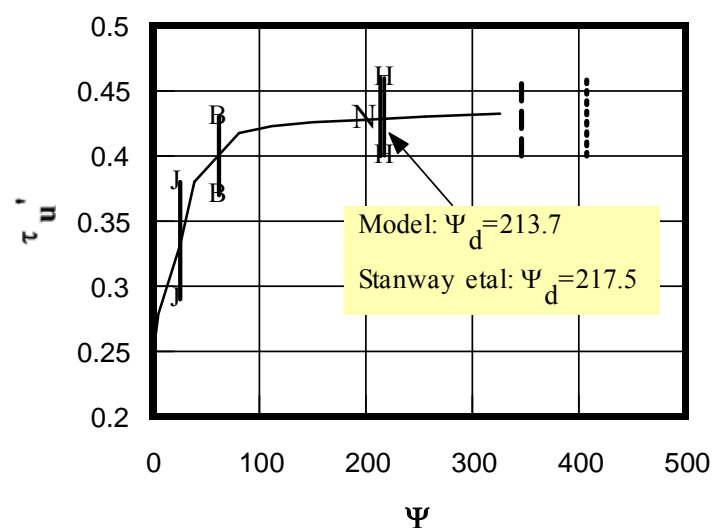

$\Psi$ $d / a=5, b / t=180$

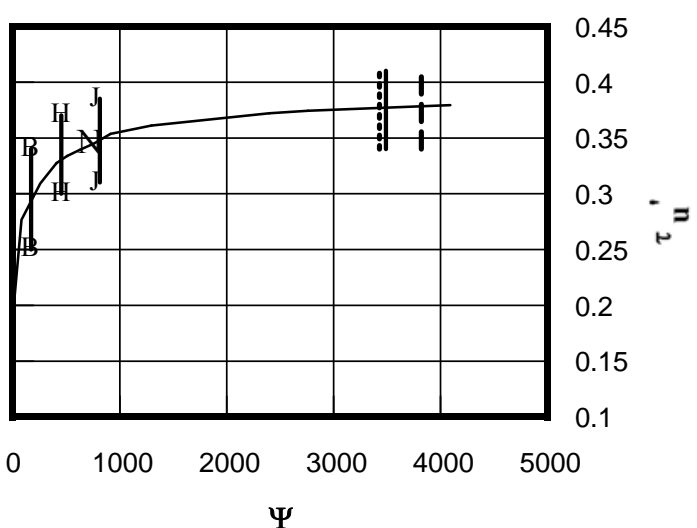

AASHTO

Horne \& Grayson

T- Rahal \& Harding Stanway et al N $\Psi_{\text {ssu }}$

Fig. 14 Comparison of the stiffener flexural rigidity $\Psi_{\mathrm{d}}$ required by the proposed model and the existing methods, with the FE $\tau_{\mathrm{u}}{ }^{\prime}$ vs. $\Psi$ results. Single-sided flat bar stiffeners $\left(\mathrm{h}_{\mathrm{s}} / \mathrm{t}_{\mathrm{s}}=10\right) \sigma_{0 \mathrm{p}}=\sigma_{0 \mathrm{~s}}=355 \mathrm{~N} / \mathrm{mm}^{2}$. $\Psi=\mathrm{EI}_{\mathrm{s}} / \mathrm{Db}, \mathrm{I}_{\mathrm{s}}$ as in Eq. (26). Pure shear 